\title{
Rules for Magnetic Exchange in Azulene-Bridged Biradicals: quo vadis?
}

Patrick Hewitt, ${ }^{1}$ David A. Shultz, ${ }^{1 *}$ and Martin L. Kirk ${ }^{2 *}$

${ }^{1}$ Department of Chemistry, North Carolina State University, Raleigh, North Carolina 27695-8204.

${ }^{2}$ Department of Chemistry, The University of New Mexico, MSC03 2060, 1 University of New Mexico, Albuquerque, New Mexico 87131-0001.

Email: shultz@ncsu.edu; mkirk@unm.edu

\section{Table of Contents}

$\begin{array}{lc}\text { X-Ray Diffraction Results } & \text { S1 } \\ \text { EPR Results } & \text { S7 } \\ \text { Magnetic Susceptibility } & \text { S7 } \\ \text { NMR Spectra } & \text { S10 } \\ \text { Mass Spectrometry Results } & \text { S22 }\end{array}$

X-Ray Diffraction. A dark green plate-like specimen of $\mathrm{C}_{111} \mathrm{H}_{126} \mathrm{~B}_{2} \mathrm{Cl}_{6} \mathrm{~N}_{12} \mathrm{O}_{4} \mathrm{Zn}_{2}$ (rds849/1,3-SQ ${ }_{2} \mathrm{Az}$ ) approximate dimensions $0.050 \mathrm{~mm} \times 0.322 \mathrm{~mm} \times 0.455 \mathrm{~mm}$, was used for the X-ray crystallographic analysis. The X-ray intensity data were measured on a Bruker-Nonius X8 Kappa APEX II system equipped with a fine-focus sealed tube (MoK $\alpha, \lambda=0.71073 \AA$ ) and a graphite monochromator. The total exposure time was 17.50 hours. The frames were integrated with the Bruker SAINT software package using a narrow-frame algorithm. The integration of the data using a triclinic unit cell yielded a total of 154401 reflections to a maximum $\theta$ angle of $28.75^{\circ}(0.74 \AA$ resolution), of which 27180 were independent (average redundancy 5.681, completeness = $\left.99.8 \%, R_{\text {int }}=5.16 \%, R_{\text {sig }}=4.21 \%\right)$ and $20990(77.23 \%)$ were greater than $2 \sigma\left(F^{2}\right)$. The final cell constants of $\underline{a}=12.3577(5) \AA, \underline{b}=12.9693(6) \AA, \underline{c}=33.4949(14) \AA, \alpha=97.2636(13)^{\circ}, \beta=$ $95.6609(13)^{\circ}, \gamma=97.5826(14)^{\circ}$, volume $=5242.2(4) \AA^{3}$, are based upon the refinement of the $X Y Z-$ centroids of 9730 reflections above $20 \sigma(I)$ with $4.308^{\circ}<2 \theta<56.61^{\circ}$. Data were corrected for absorption effects using the Multi-Scan method (SADABS). The ratio of minimum to maximum apparent transmission was 0.925. The calculated minimum and maximum transmission coefficients (based on crystal size) are 0.6895 and 0.7458 .

The final anisotropic full-matrix least-squares refinement on $\mathrm{F}^{2}$ with 1259 variables converged at R1 $=5.96 \%$, for the observed data and $\mathrm{WR} 2=15.45 \%$ for all data. The goodness-of-fit was 1.041 . The largest peak in the final difference electron density synthesis was $1.639 \mathrm{e}^{-} / \AA^{3}$ and the largest hole was $-2.102 \mathrm{e}^{-} / \AA^{3}$ with an RMS deviation of $0.092 \mathrm{e}^{-} / \AA^{3}$. On the basis of the final model, the calculated density was $1.303 \mathrm{~g} / \mathrm{cm}^{3}$ and $F(000), 2160 \mathrm{e}^{-}$.

A dark purple rod-like specimen of $\mathrm{C}_{68.50} \mathrm{H}_{80} \mathrm{BCl}_{5} \mathrm{~N}_{8} \mathrm{O}_{4} \mathrm{Zn}$ (rds946/1,3-SQ-Az-NN), approximate dimensions $0.062 \mathrm{~mm} \times 0.096 \mathrm{~mm} \times 0.215 \mathrm{~mm}$, was used for the X-ray crystallographic analysis. 
The X-ray intensity data were measured on a Bruker D8 VENTURE k-geometry diffractometer system equipped with an Incoatec I $\mu \mathrm{S} 3.0$ microfocus sealed tube ( $\mathrm{Cu} K \alpha, \lambda=1.54178 \AA$ ) and a multilayer mirror monochromator. The total exposure time was 3.92 hours. The frames were integrated with the Bruker SAINT software package using a narrow-frame algorithm. The integration of the data using a triclinic unit cell yielded a total of 108098 reflections to a maximum $\theta$ angle of $74.83^{\circ}(0.80 \AA$ resolution), of which 13615 were independent (average redundancy 7.940 , completeness $\left.=99.6 \%, R_{\text {int }}=4.30 \%, R_{\text {sig }}=2.37 \%\right)$ and $12128(89.08 \%)$ were greater than $2 \sigma\left(F^{2}\right)$. The final cell constants of $\underline{a}=12.0129(3) \AA, \underline{b}=13.2970(3) \AA, \underline{c}=21.9252(6) \AA, \alpha=$ $103.3060(10)^{\circ}, \beta=101.2800(10)^{\circ}, \gamma=92.218(2)^{\circ}$, volume $=3329.49(15) \AA^{3}$, are based upon the refinement of the $X Y Z$-centroids of 9644 reflections above $20 \sigma(I)$ with $6.857^{\circ}<2 \theta<148.9^{\circ}$. Data were corrected for absorption effects using the Multi-Scan method (SADABS). The ratio of minimum to maximum apparent transmission was 0.898 . The calculated minimum and maximum transmission coefficients (based on crystal size) are 0.5860 and 0.8460 .

The structure was solved and refined using the Bruker SHELXTL Software Package, using the space group $\mathrm{P}-1$, with $\mathrm{Z}=2$ for the formula unit, $\mathrm{C}_{68.50} \mathrm{H}_{80} \mathrm{BCl}_{5} \mathrm{~N}_{8} \mathrm{O}_{4} \mathrm{Zn}$. The final anisotropic fullmatrix least-squares refinement on $\mathrm{F}^{2}$ with 834 variables converged at $\mathrm{R} 1=6.53 \%$, for the observed data and WR2 $=18.99 \%$ for all data. The goodness-of-fit was 1.057 . The largest peak in the final difference electron density synthesis was $1.399 \mathrm{e}^{-} / \AA^{3}$ and the largest hole was $-1.316 \mathrm{e}^{-}$ $/ \AA^{3}$ with an RMS deviation of $0.096 \mathrm{e}^{-} / \AA^{3}$. On the basis of the final model, the calculated density was $1.329 \mathrm{~g} / \mathrm{cm}^{3}$ and $F(000), 1398 \mathrm{e}^{-}$. 


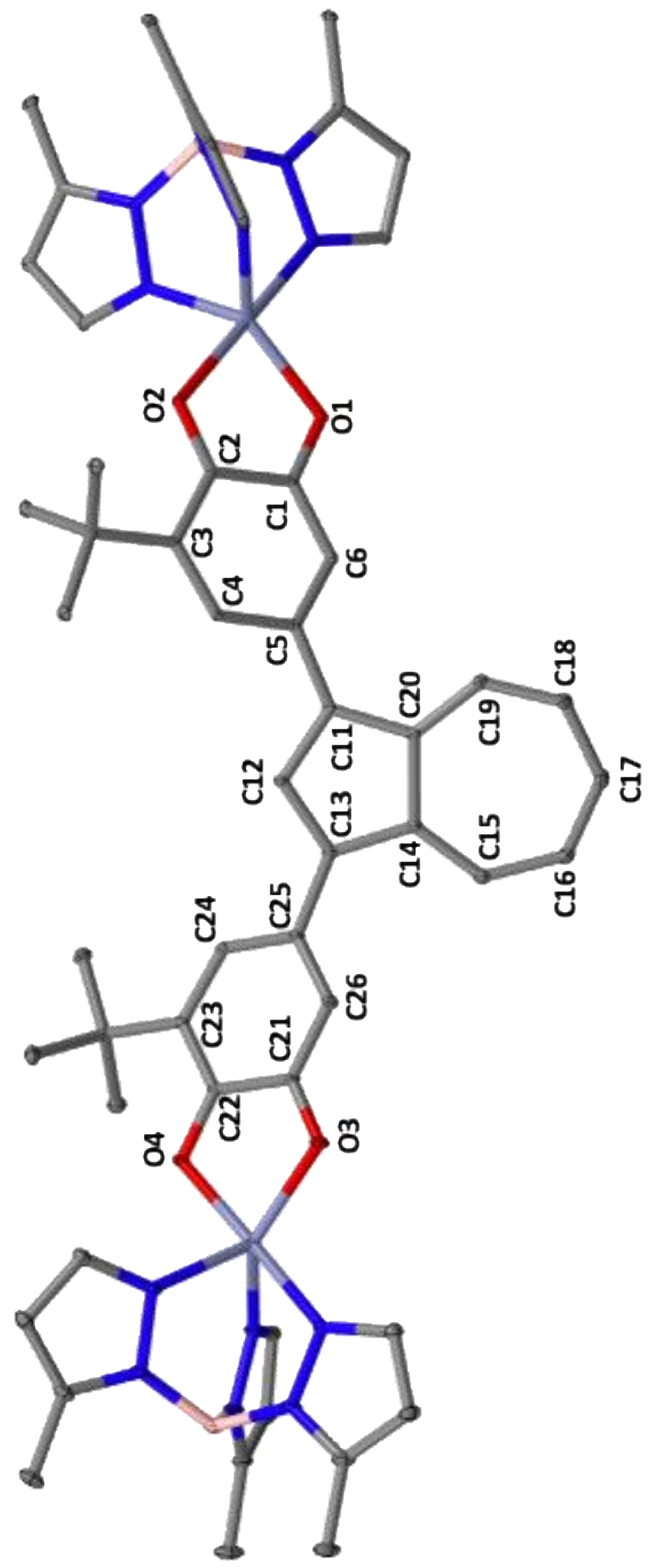

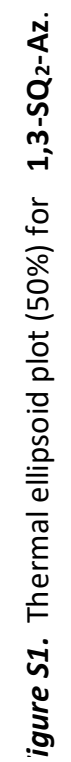




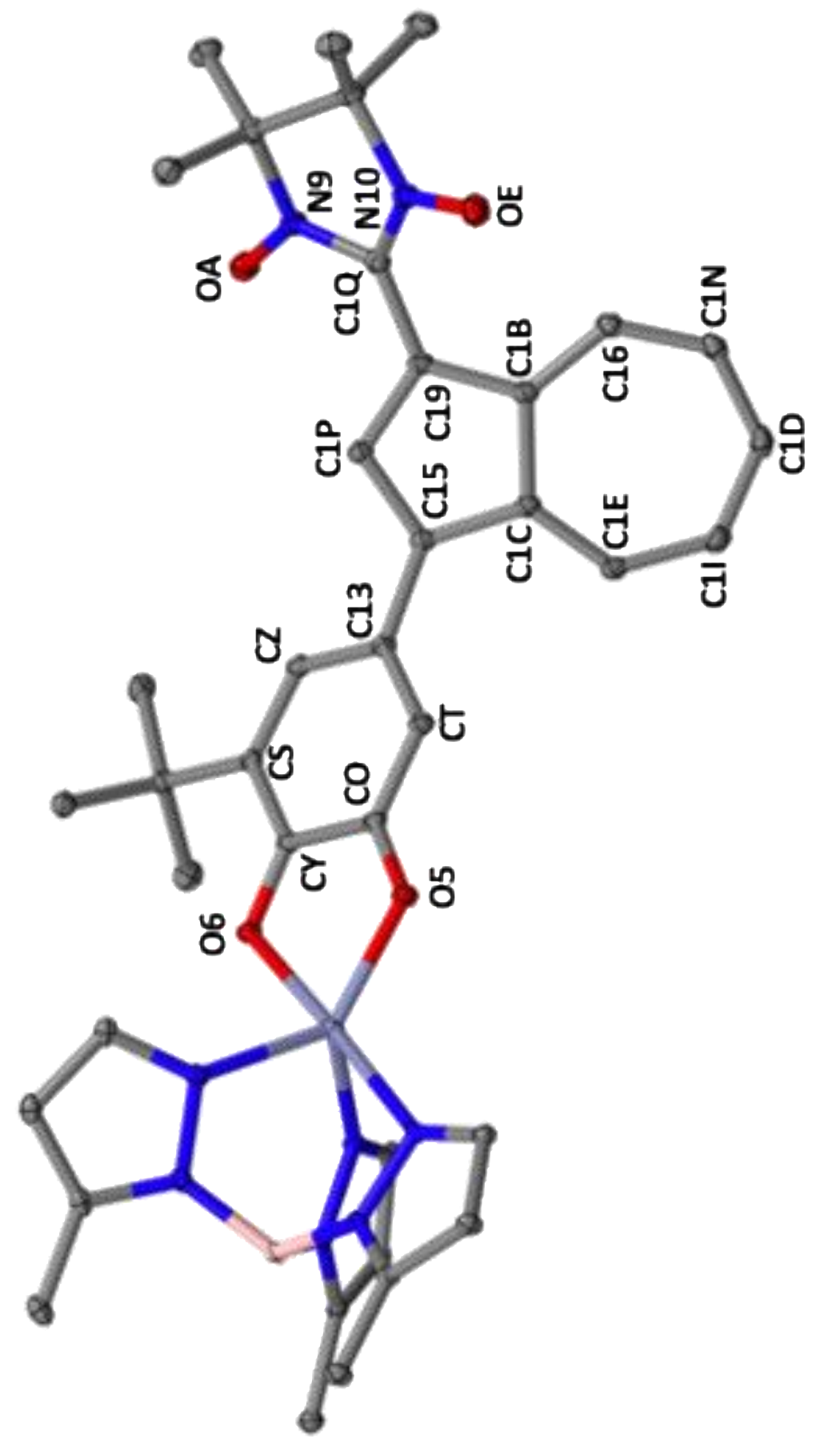

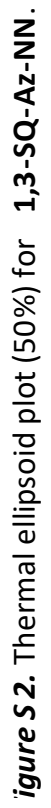


Table S1. Crystallographic Data for 1,3-SQ ${ }_{2} \mathrm{Az}$ and 1,3-SQ-Az-NN.

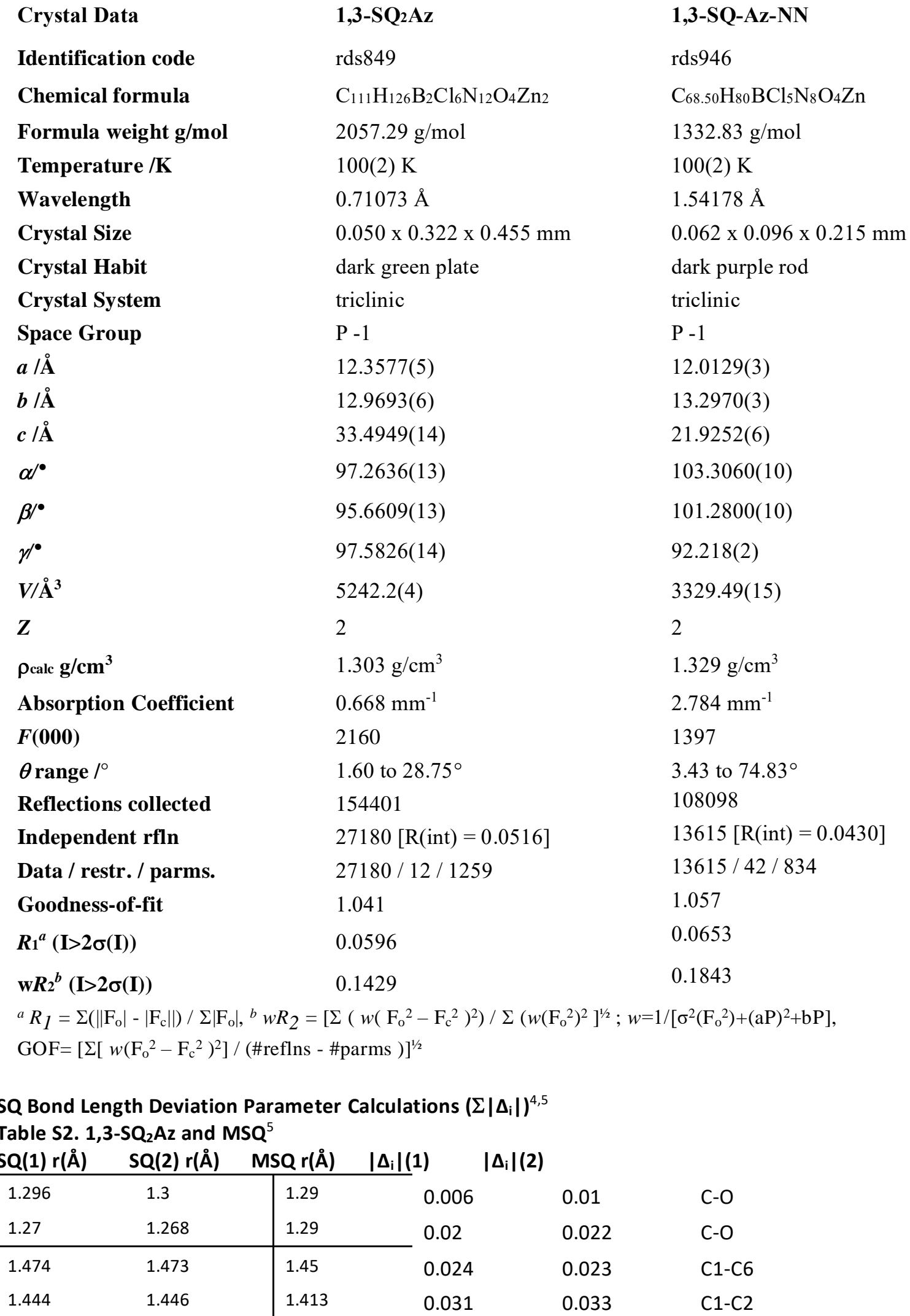




\begin{tabular}{ll|lllll}
1.369 & 1.372 & 1.373 & 0.004 & 0.001 & $\mathrm{C} 2-\mathrm{C} 3$ & \\
1.437 & 1.431 & 1.435 & 0.002 & 0.004 & $\mathrm{C} 3-\mathrm{C} 4$ & \\
1.384 & 1.391 & 1.371 & 0.013 & 0.02 & $\mathrm{C} 4-\mathrm{C} 5$ & \\
1.395 & 1.4 & 1.445 & 0.05 & 0.045 & $\mathrm{C} 5-\mathrm{C} 6$ & \\
\hline
\end{tabular}

Table S3. SQ bond lengths for 1,3-SQ-Az-NN and $\mathrm{MSQ}^{5}$

\begin{tabular}{lll} 
SQ $\mathbf{r}(\AA \AA)$ & MSQ $\mathbf{r}(\AA \AA)$ & $\left|\Delta_{\mathrm{i}}\right|$ \\
\hline 1.298 & 1.29 & 0.008 \\
1.266 & 1.29 & 0.024 \\
\hline 1.469 & 1.45 & 0.019 \\
1.455 & 1.413 & 0.042 \\
1.367 & 1.373 & 0.006 \\
1.44 & 1.435 & 0.005 \\
1.378 & 1.371 & 0.007 \\
1.403 & 1.445 & 0.042 \\
\hline & & $\mathbf{0 . 1 5 3}$
\end{tabular}

$$
=\Sigma\left|\Delta_{i}\right| \text { for 1,3-SQ-Az-NN }
$$

Table S4. SQ bond lengths for 1,3-SQ-m-Ph-NN ${ }^{6}$ and $\mathrm{MSQ}^{5}$

SQ r(Å)

\begin{tabular}{l|c}
\hline 1.266 & 1.29 \\
1.289 & 1.29 \\
\hline 1.471 & 1.45 \\
1.451 & 1.413 \\
1.374 & 1.373 \\
1.438 & 1.435 \\
1.381 & 1.371 \\
1.401 & 1.445 \\
\hline
\end{tabular}

$\left|\Delta_{\mathrm{i}}\right|$

0.024

0.001

0.021

0.038

0.001

0.003

0.01

0.044

$0.142=\Sigma\left|\Delta_{\mathrm{i}}\right|$ for 1,3-SQ-m-Ph-NN

Table S5. SQ bond lengths for $1,3-\mathrm{SQ}_{2} \mathrm{~m}-\mathrm{Ph}^{7}$ and $\mathrm{MSQ}^{5}$

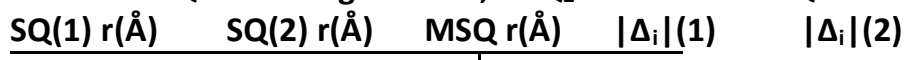

\begin{tabular}{ll|llll}
\hline 1.294 & 1.303 & 1.29 & 0.004 & 0.013 \\
1.272 & 1.279 & 1.29 & 0.018 & 0.011 \\
\hline 1.448 & 1.459 & 1.45 & 0.002 & 0.009 \\
1.454 & 1.433 & 1.413 & 0.041 & 0.02 \\
1.369 & 1.354 & 1.373 & 0.004 & 0.019 & \\
1.415 & 1.426 & 1.435 & 0.02 & 0.009 & \\
1.376 & 1.379 & 1.371 & 0.005 & 0.008 & \\
1.411 & 1.404 & 1.445 & 0.034 & 0.041 & \\
\hline \multicolumn{7}{r}{} \\
\end{tabular}




\section{References}

1) Bruker-AXS Inc. (2014), Madison Wisconsin, USA.

2) Sheldrick, G. M. (2008). Acta Cryst. A64, 112-122.

3) Dolomanov, O.V.; Bourhis, L.J.; Gildea, R.J.; Howard, J.A.K.; Puschmann, H., OLEX2: A complete structure solution, refinement and analysis program (2009). J. Appl. Cryst., 42, 339-341.

4) "Molecular structure of and exchange coupling in a bis(semiquinone) complex," Shultz, D. A.; Bodnar, S. H.; Kampf, J. W. Chem. Commun. 2001,93-94.

5) "Both an Oxidation/Reduction Sequence and Deprotonation of a Unique Paramagnetic Ligand Lead to a Mixed-Valent Complex," Shultz, D. A.; Bodnar, S. H.; Kumar, R. K.; Kampf, J. W. J. Am. Chem. Soc. 1999, 121, 10664-10665.

6) "Electronic and Exchange Coupling in a Cross-Conjugated D-B-A Biradical: Mechanistic Implications for Quantum Interference Effects," Kirk, M. L.; Shultz, D. A.; Stasiw, D. E.; HabelRodriguez, D.; Stein, B.; Boyle, P. D. J. Am. Chem. Soc. 2013, 135, 14713-14725.

7) "Synthesis of and structure-property relationships in zinc complexes of bis-metaphenylene semiquinone biradical species," Sloop, J. C.; Shultz, D. A.; Coote, T.; Shepler, B.; Sullivan, U.; Kampf, J. W.; Boyle, P. D. J. Phys. Org. Chem. 2012, 25, 314-321.

Electron Paramagnetic Resonance. EPR spectra were recorded on a Brüker ELEXSYS-II E500 CW EPR spectrometer with low temperature capabilities. Samples ca. $2 \mathrm{mM}$ in biradical (frozen solution experiments) were prepared in freshly distilled 2-methyl-tetrahydrofuran or toluene, degassed, and the spectra collected in quartz EPR tubes.

The fluid Solution EPR spectrum of 1-SQ-Az along with a simulation shown in Fig. S3.

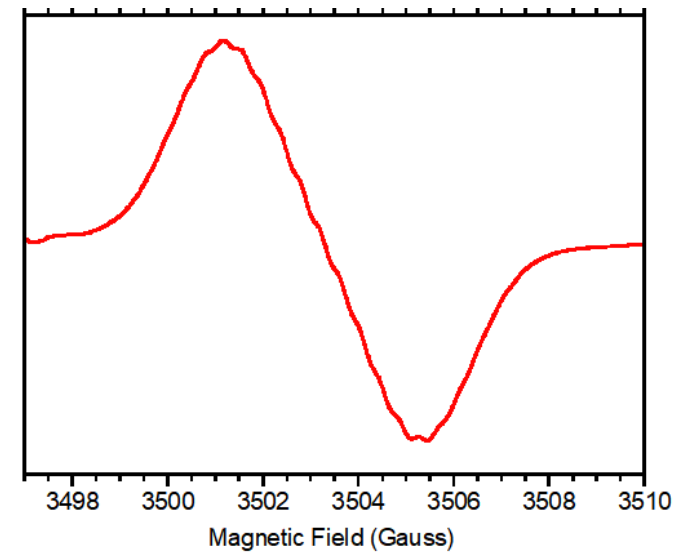

Figure S3. EPR spectrum of 1-SQ-Az collected at 298 Kelvin as a $1 \mu \mathrm{M}$ solution in 2-methyltetrahydrofuran. The number of hyperfine lines is consistent with extensive delocalization into the azulene ring(s), but the accompanying linewidth precludes meaningful simulation.

Magnetic Susceptibility and Magnetization. Magnetic susceptibility measurements were collected on a Quantum Design MPMS-XL7 SQUID magnetometer with an applied field of 0.7 T. A crystalline sample ( $20 \mathrm{mg}$ ) was loaded into a gel cap/straw sample holder and mounted to the sample rod with Kapton tape for variable temperature measurements. Raw data were corrected 
with Pascal's constants as a first approximation for molecular diamagnetism followed by a straight line correction to all data for diamagnetic response of sample container where the slope of the line represents the residual diamagnetic correction. The Magnetic susceptibility data were fit using a field-independent van Vleck expression, $\chi_{\text {eff }} \mathrm{T}=[\chi /(1-\theta \chi)] \mathrm{T}$, where $\theta=\frac{2 z J_{\text {inter }}^{\prime}}{N g^{2} \beta^{2}}$, and $\chi=$ $\frac{0.75 g^{2}}{3+\exp \left(\frac{-2 J_{S Q B N N}}{0.695 \cdot T}\right)}$, and $J_{\text {SQNN }}$ is the SQ-Bridge-NN magnetic exchange parameter. ${ }^{1}$ The origin of $\mathrm{zJ}$ 'inter may be zero-field splitting, intermolecular interactions, saturation effects, or some combination of all three. ${ }^{1-2}$ In our data, the effects of $z J^{\prime}$ inter are negligible compared to $J_{\text {SQ-B-NN, }}$ and varying results in $10-15 \%$ changes in $J_{S Q-B-N N}$, which is insufficient to alter either our discussion or conclusions. In fact, by omitting the $\chi_{\text {para }} \bullet T$ data points below $10 \mathrm{~K}$, the data can be fit adequately without the $z J^{\prime}$ inter term. Typically, the small deviation of the $g$-values (as a fit parameter) from the expected spin-only value of $\sim 2.00$ can be the result of minute ( 1\%) weighing errors. We note that excellent fits required no "J-strain," suggesting that thermal (de)population of vibrational/torsional levels have no effect on the magnetic data, in accord with our published results on other SQ-Bridge-NN molecules.

Magnetization data (Fig. S4) were collected from the same samples as the magnetic susceptibility (see text Fig. 3), and the former data were collected at $2 \mathrm{~K}$ with applied magnetic fields of 0 to $7 \mathrm{~T}$.

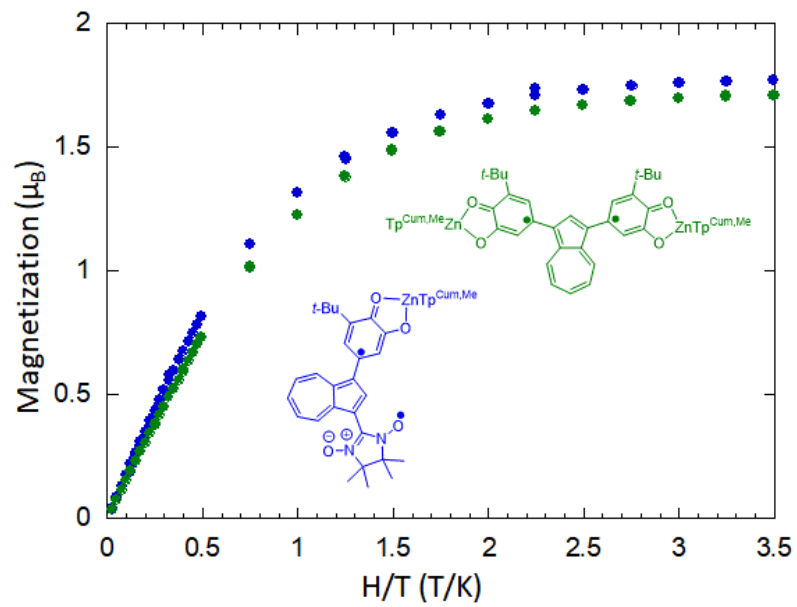

Figure S4. Magnetization plots for Complexes 1,3-SQ $2 \mathrm{Az}$ and 1,3-SQ-Az-NN collected at 2 Kelvin. Saturation values for 1,3-SQ $\mathbf{A z}$ and 1,3-SQ-Az-NN are $\sim 82 \%$ of the theoretical value, respectively, due to diamagnetic and monoradical impurities, and weak antiferromagnetic intermolecular interactions.

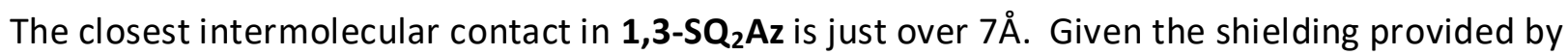
the $\mathrm{Tp}^{\mathrm{Cum}, \mathrm{Me}}$ ancillary ligands, we feel that intermolecular contact have a negligible effect on the magnetic susceptibility. The same argument applys to SQ---SQ and SQ---NN interactions in 1,3SQ-Az-NN. The closest intermolecular contact in 1,3-SQ-Az-NN is $\sim 3.2 \AA$ (Fig. S5). Haraguchi et al. ((Azulene-1,3-diyl)-bis(nitronyl nitroxide) and (Azulene-1,3-diyl)-bis(iminonitroxide) and Their Copper Complexes" Chem. Asian J. 201712 (22), 2929-2941; cited ref. 42 in the manuscript) list intermolecular contacts of $\sim 4 \AA$ and attribute measured exchange to 
intramolecular interactions. The 3.2 ̊ NO---NO contact in 1,3-SQ-Az-NN aligns N and O atoms of neighboring molecules and would result in an antiferromagnetic interaction. ${ }^{3}$

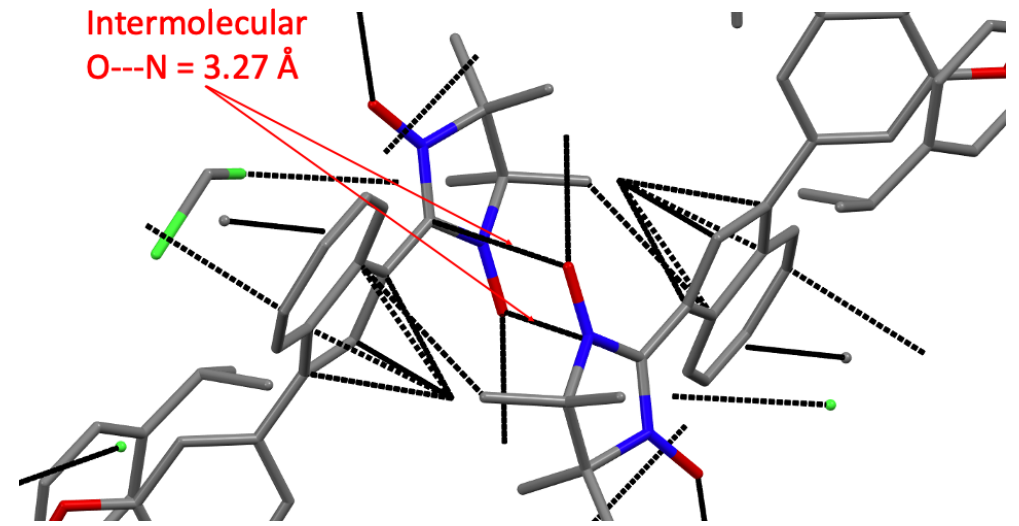

Figure S5. Intermolecular $\mathrm{N} \bullet \bullet \bullet$ C contacts of 3.27 $\mathrm{A}$ in 1,3-SQ-Az-NN. The alignment of the paramagnetic N-O atoms $\left(\mathrm{N}\right.$ are blue an $\mathrm{O}$ are red) is consistent with a weak antiferromagnetic interaction. ${ }^{3}$

Fitting the data to a dimer model ${ }^{4}$ gives $\boldsymbol{J}_{\text {intra }}(\mathrm{SQ}-\mathrm{Az}-\mathrm{NN})=+4.1 \pm 0.2 \mathrm{~cm}^{-1}$, and $\boldsymbol{J}_{\text {inter }}(\mathrm{N}-\mathrm{O})=-1.8 \pm$ $0.5 \mathrm{~cm}^{-1}$. While the intermolecular coupling is substantial, the ferromagnetic intramolecular coupling is verified.

Figure S6. Dimer model fit for 1,3-SQ-Az-NN.

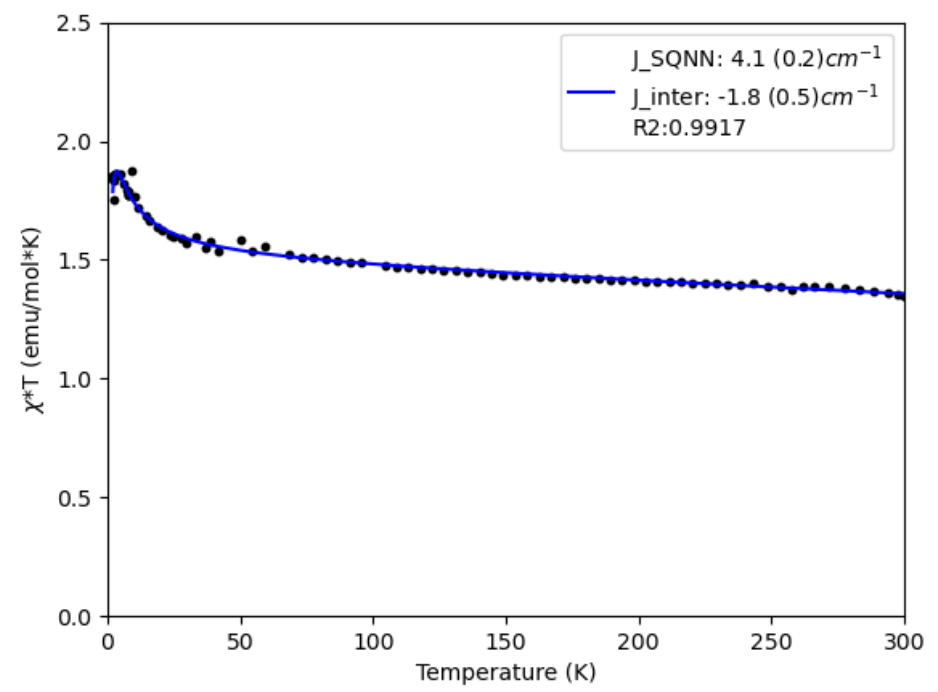

\section{References}

(1) "Magnetochemistry - Advances in Theory and Experimentation," O'Connor, C. J. Prog. Inorg. Chem. 1982, 29, 203.

(2) "Trends in Metal-Biradical Exchange Interaction for First-Row M"(Nitronyl Nitroxide-Semiquinone) Complexes," Shultz, D. A.; Vostrikova, K. E.; Bodnar, S. H.; Koo, H.-J.; Whangbo, M.-H.; Kirk, M. L.; Depperman, E. C.; Kampf, J. W. J. Am. Chem. Soc. 2003, 125, 1607-1617.

(3) Novoa, J. J.; Deumal, M., The mechanism of the through-space magnetic interactions in purely organic molecular magnets. In (Pi)-Electron Magnetism from Molecules to Magnetic Materials, Veciana, J., Ed. 2001; Vol. 100, pp 33-60.

(4) Kahn, O., Molecular Magnetism. VCH: New York, 1993. 


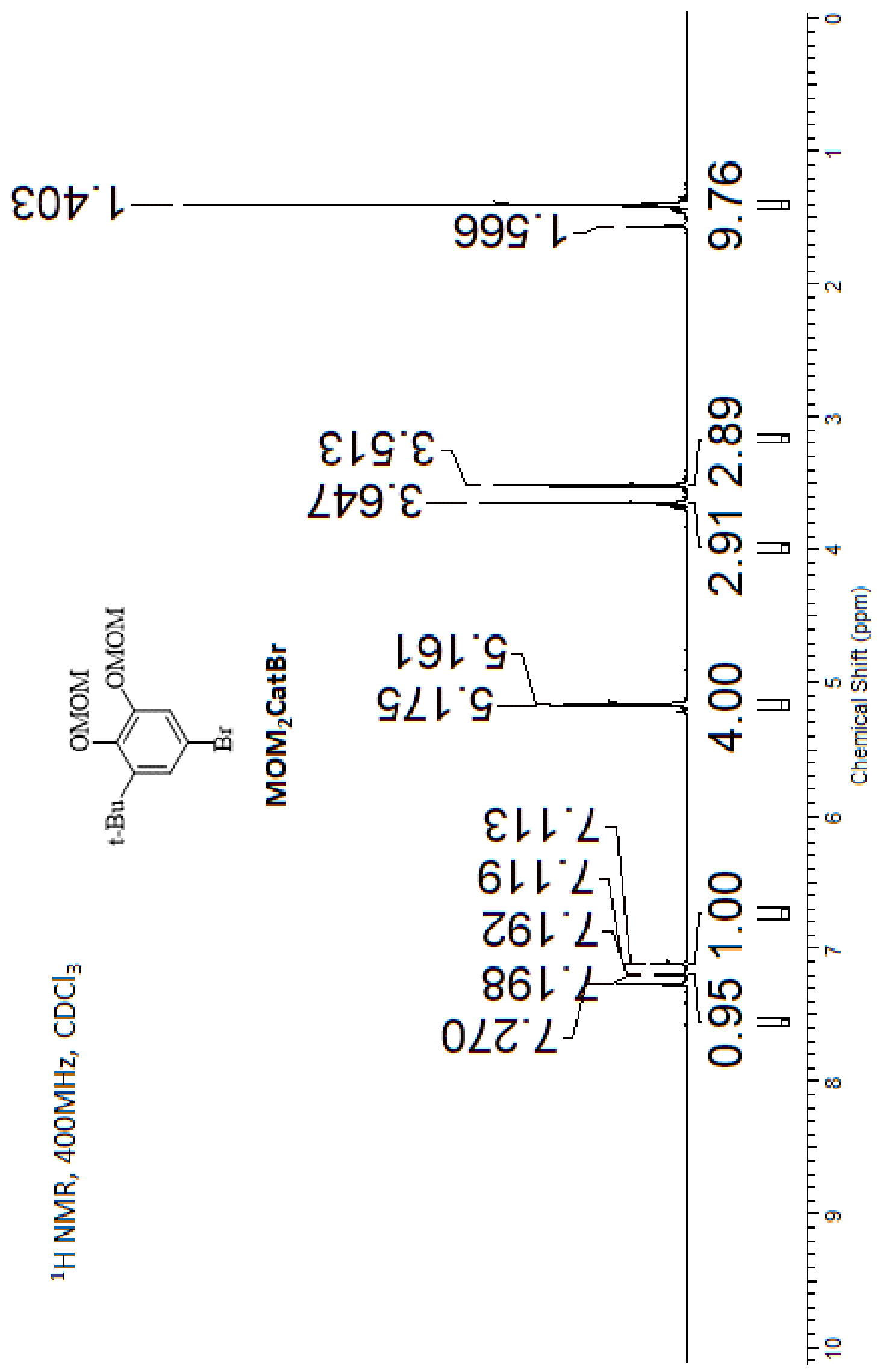




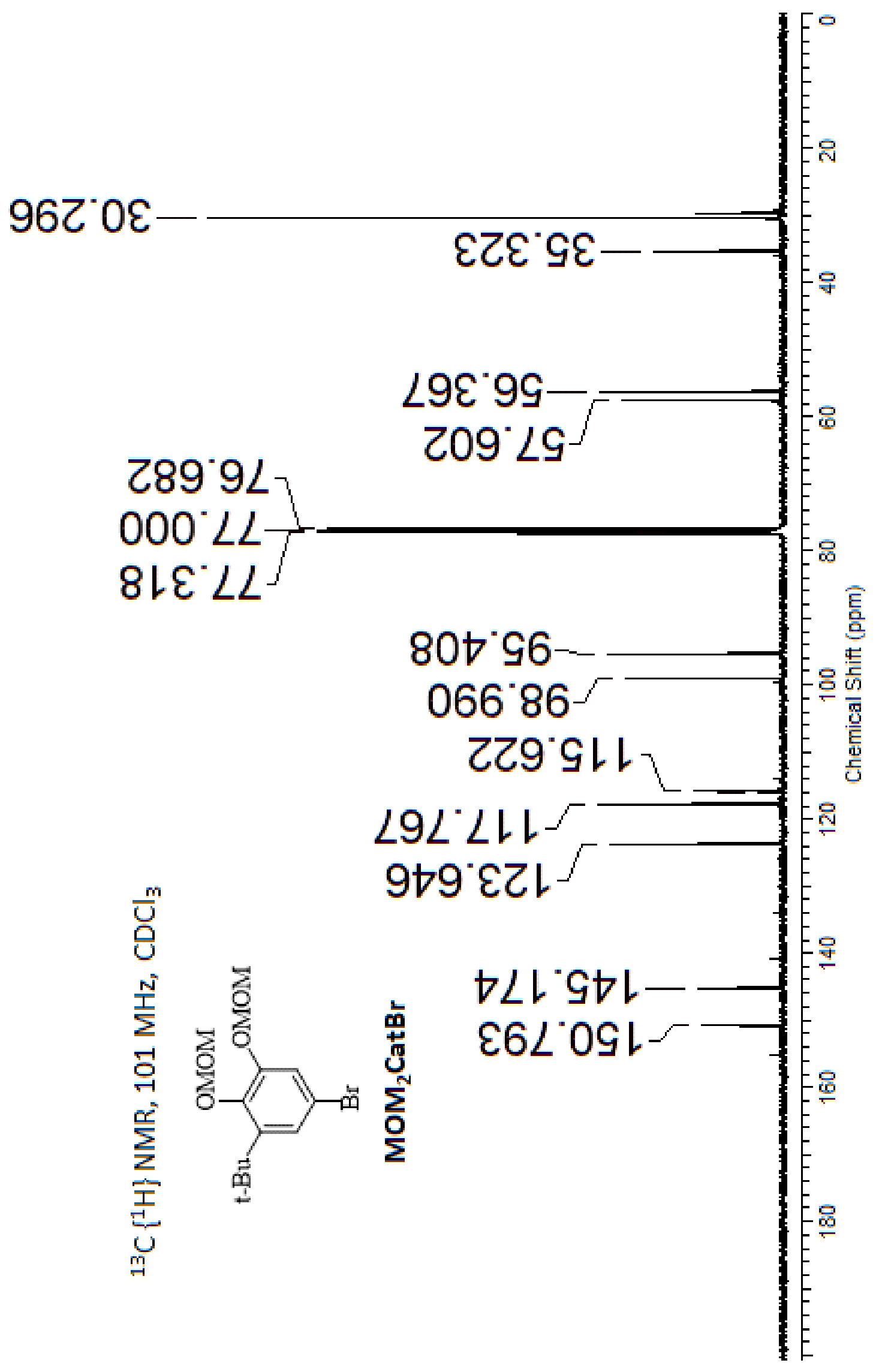




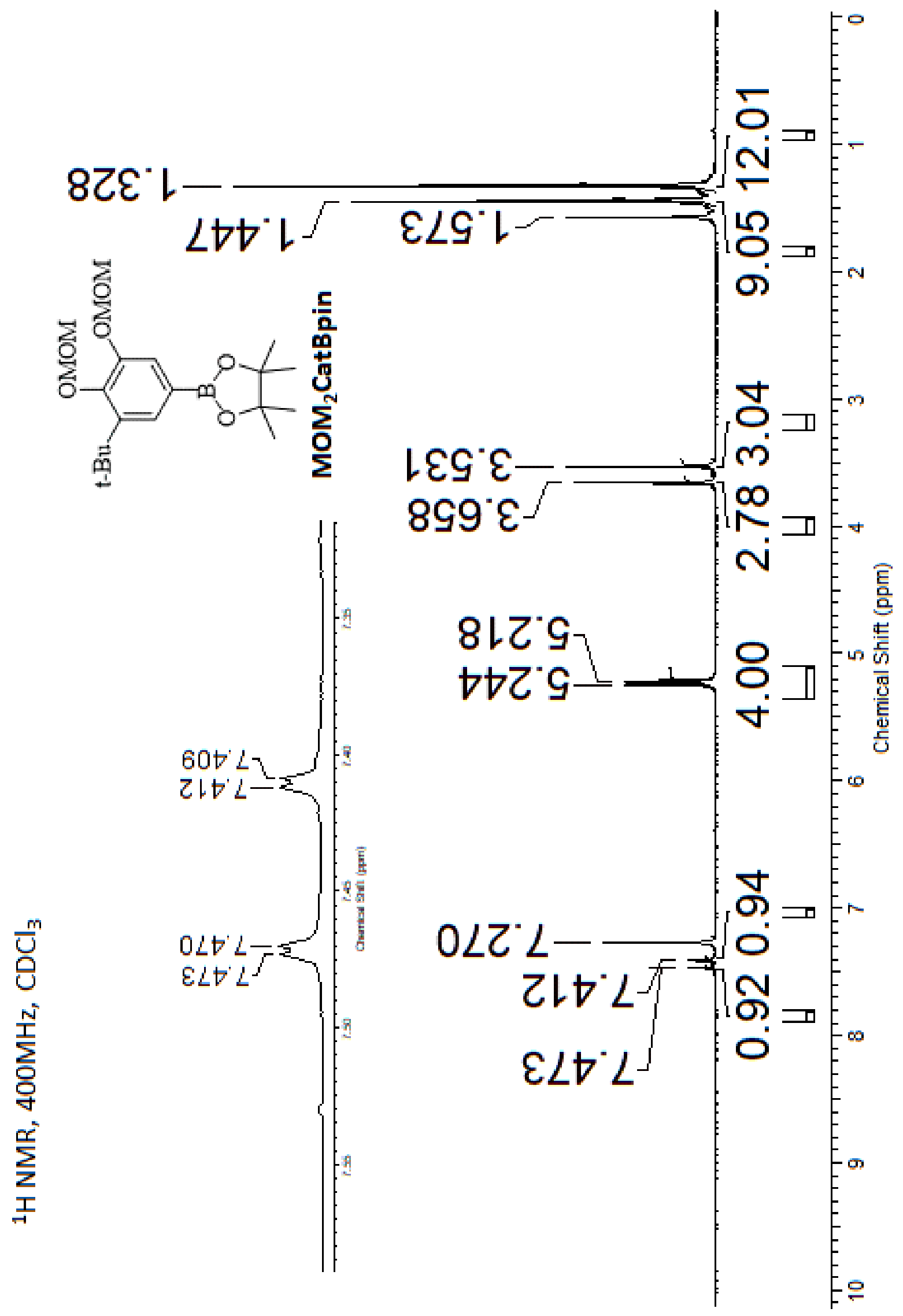




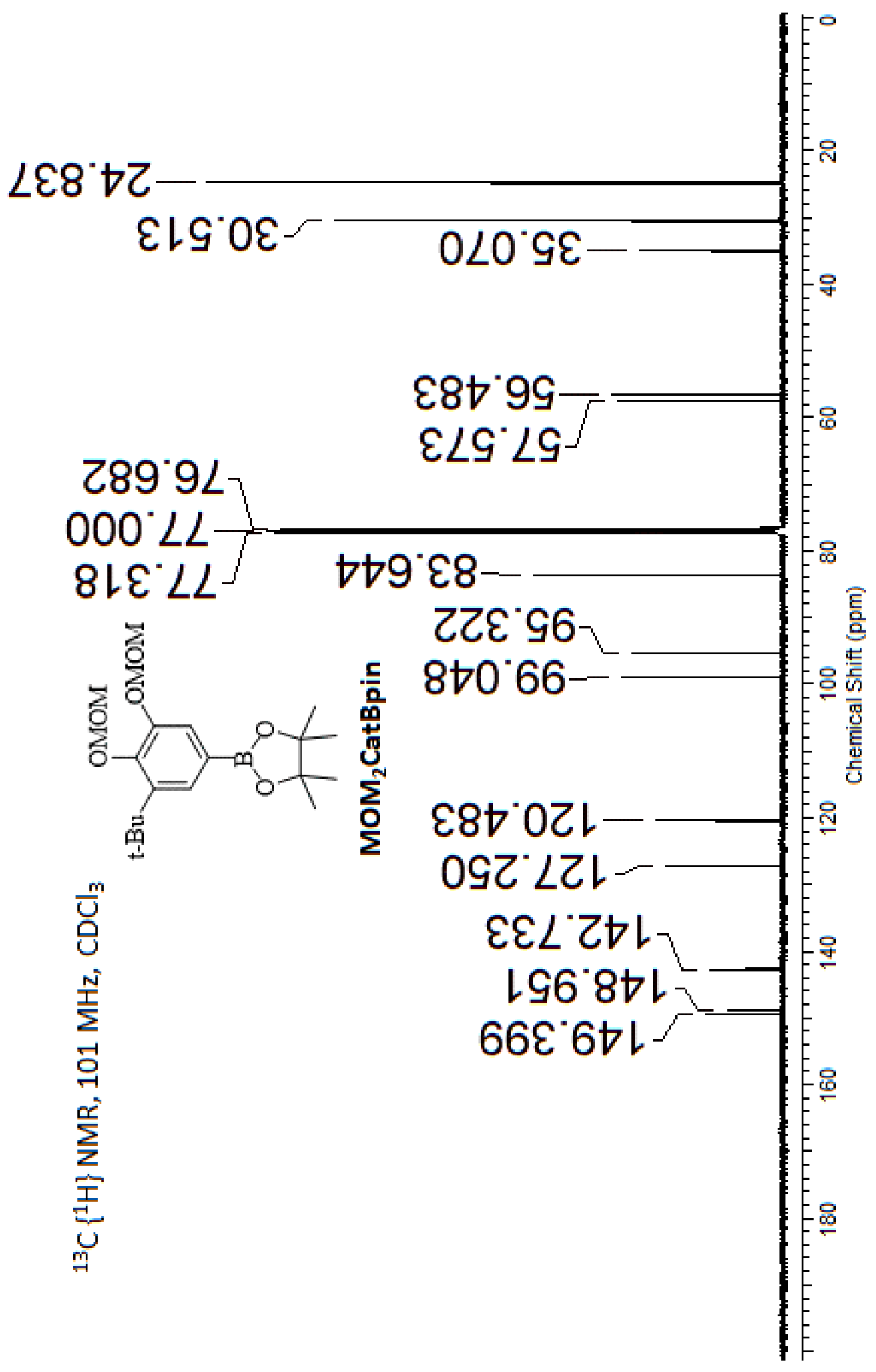




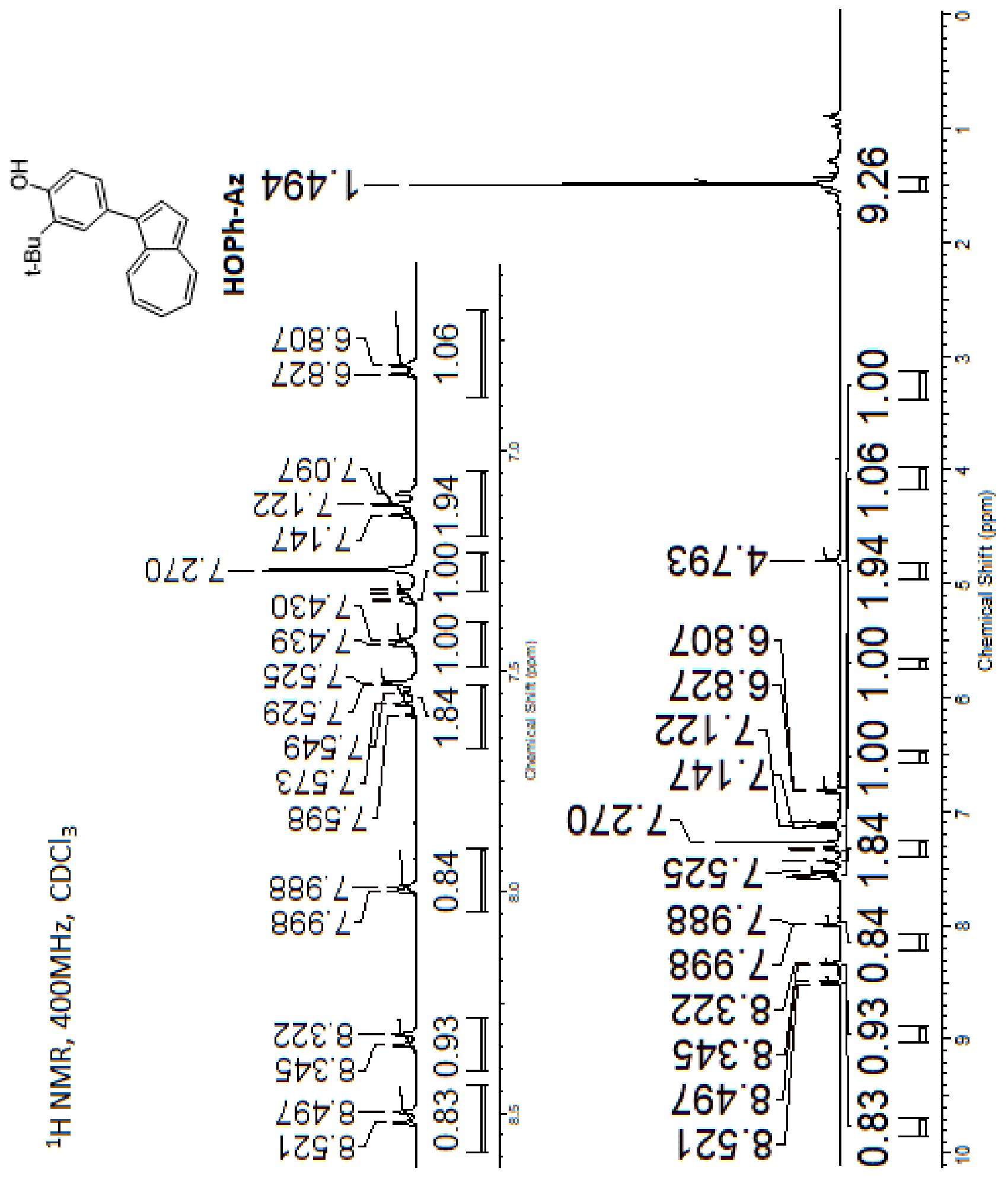




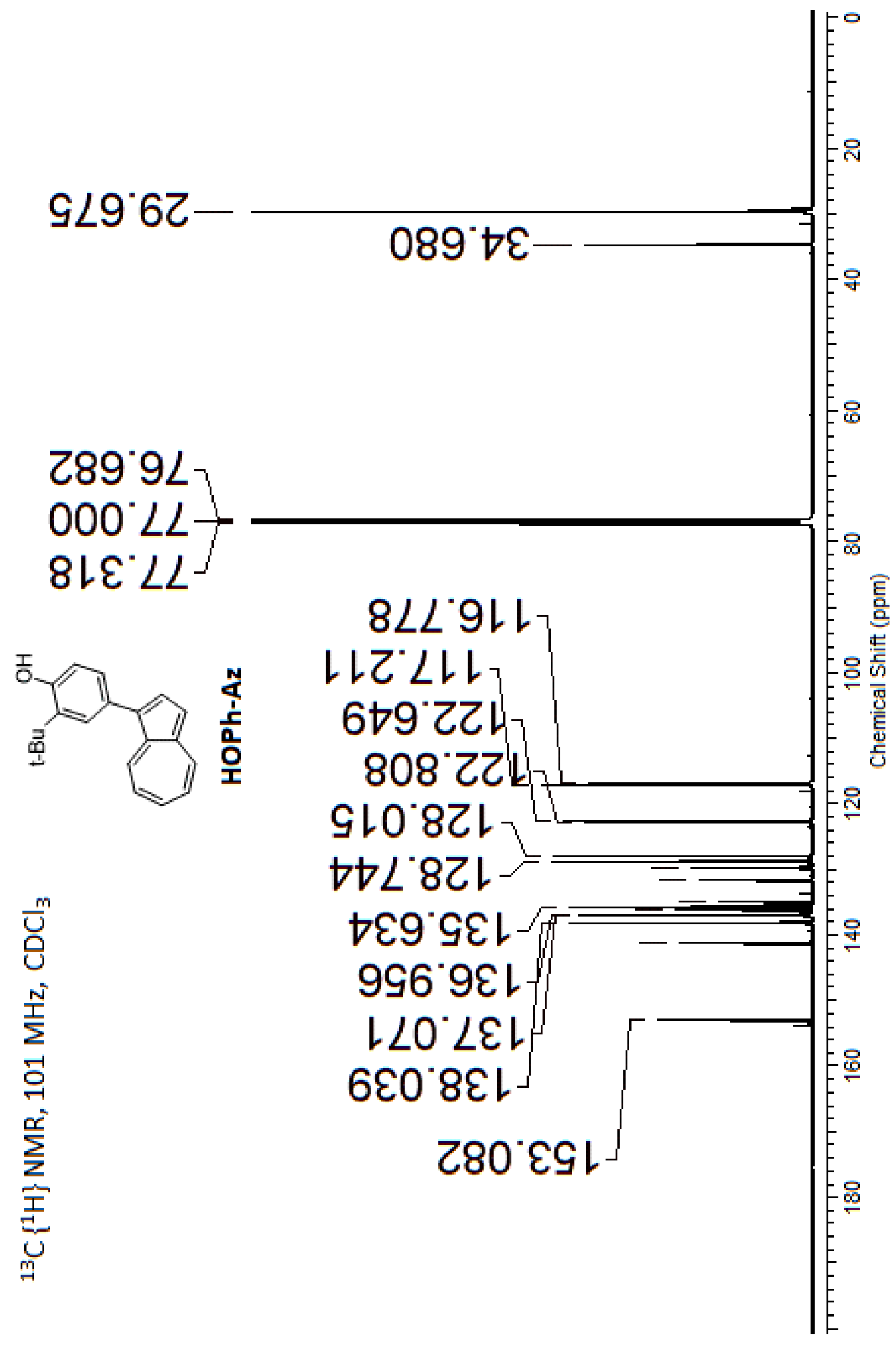




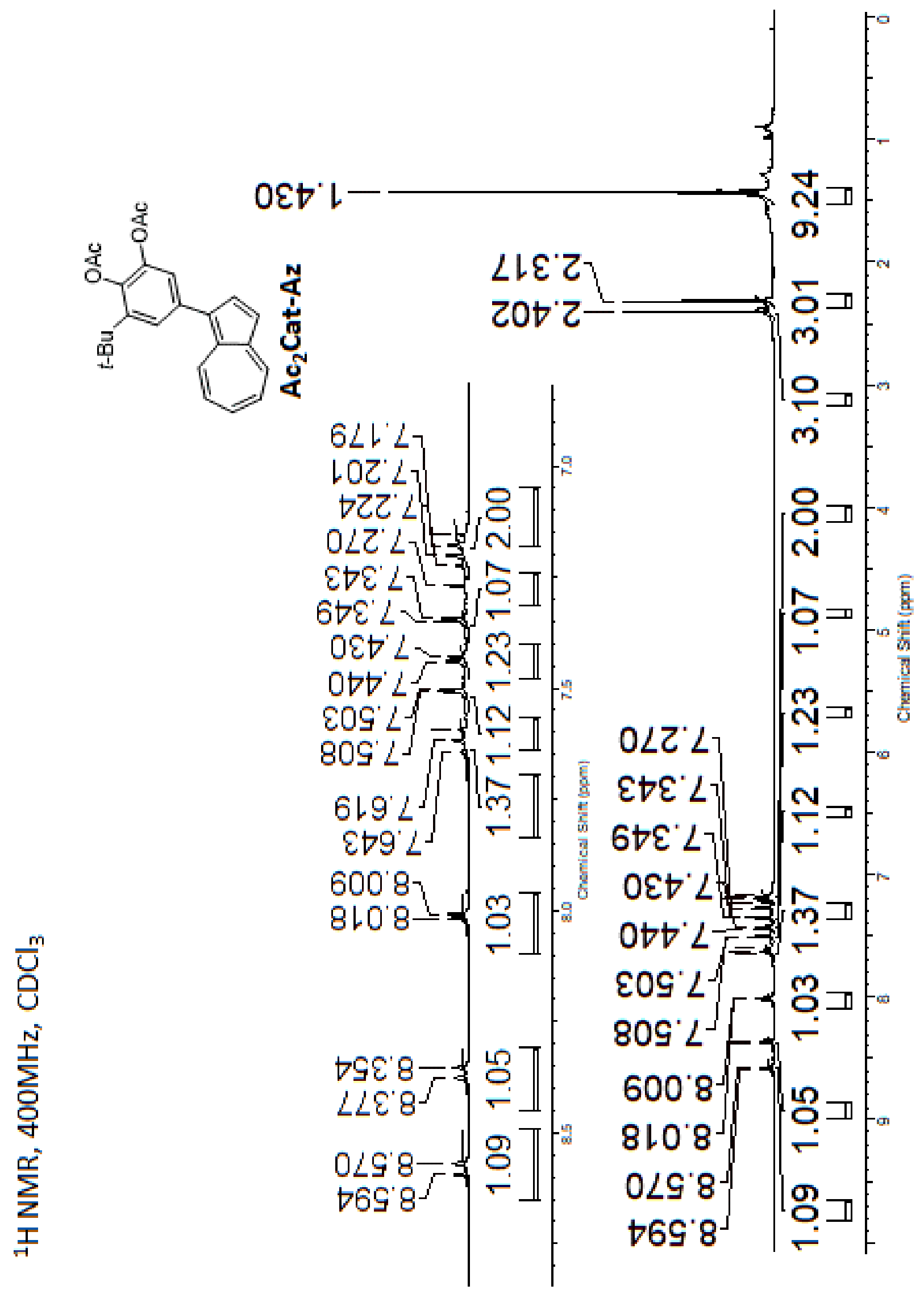




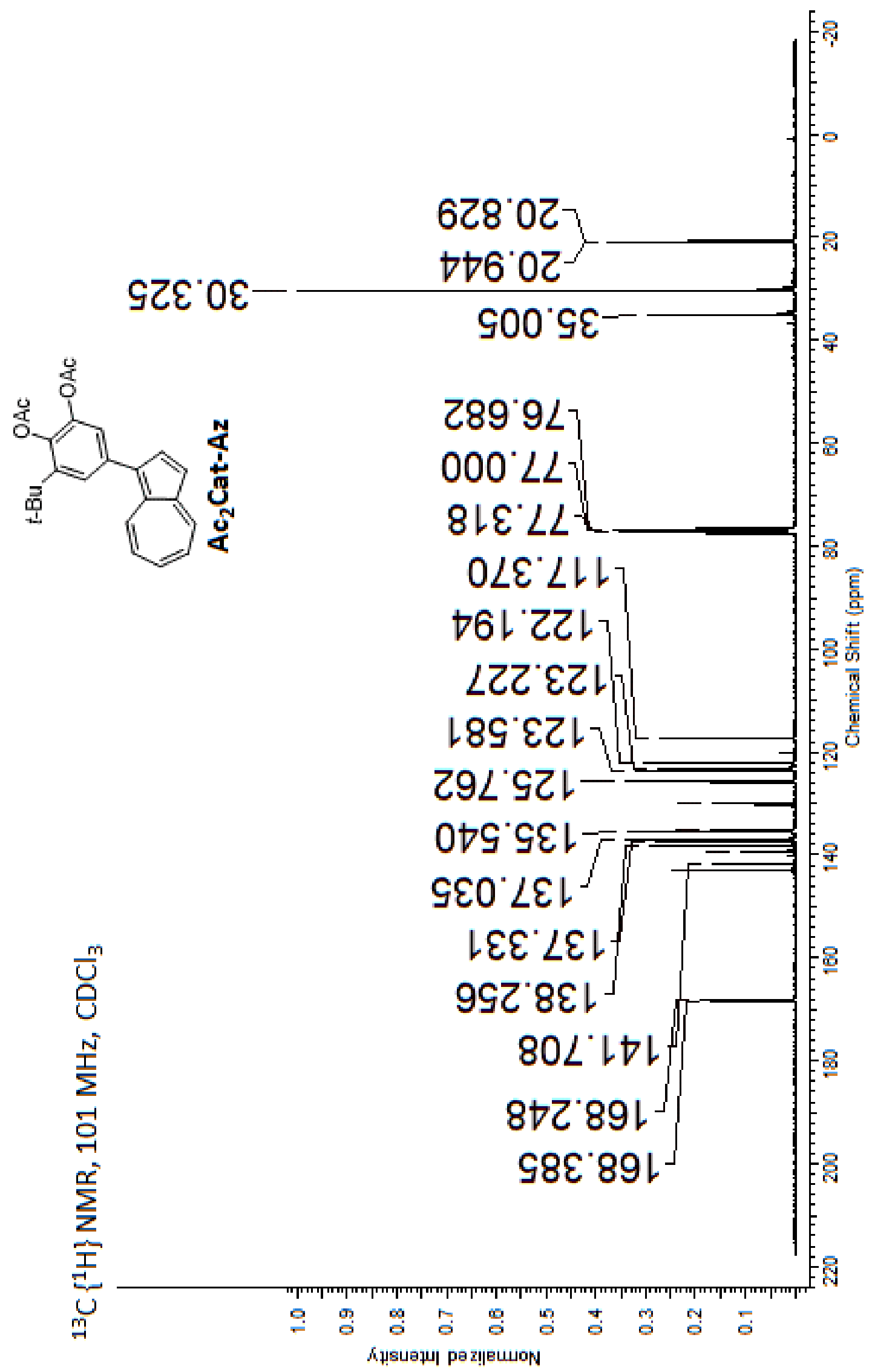




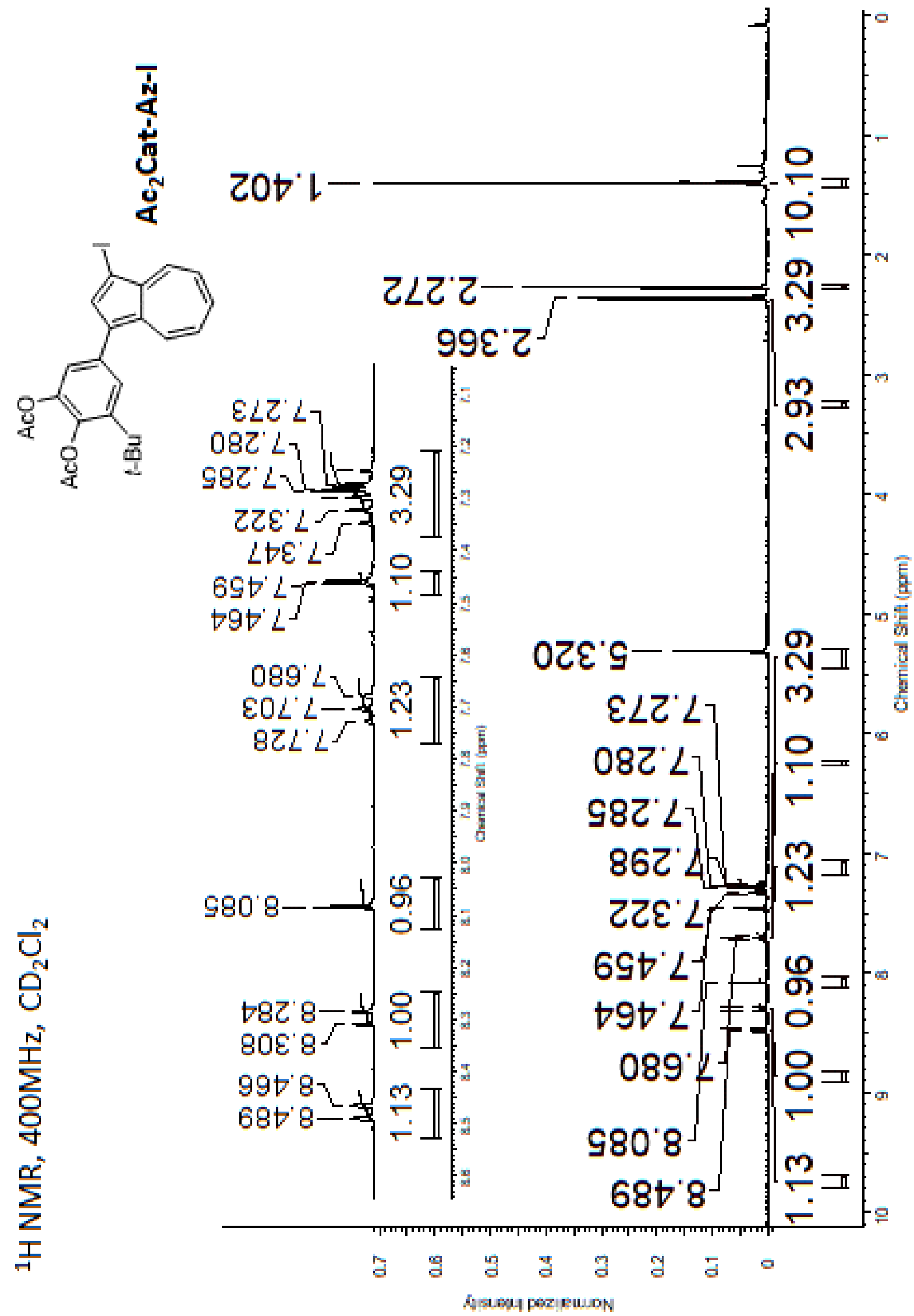




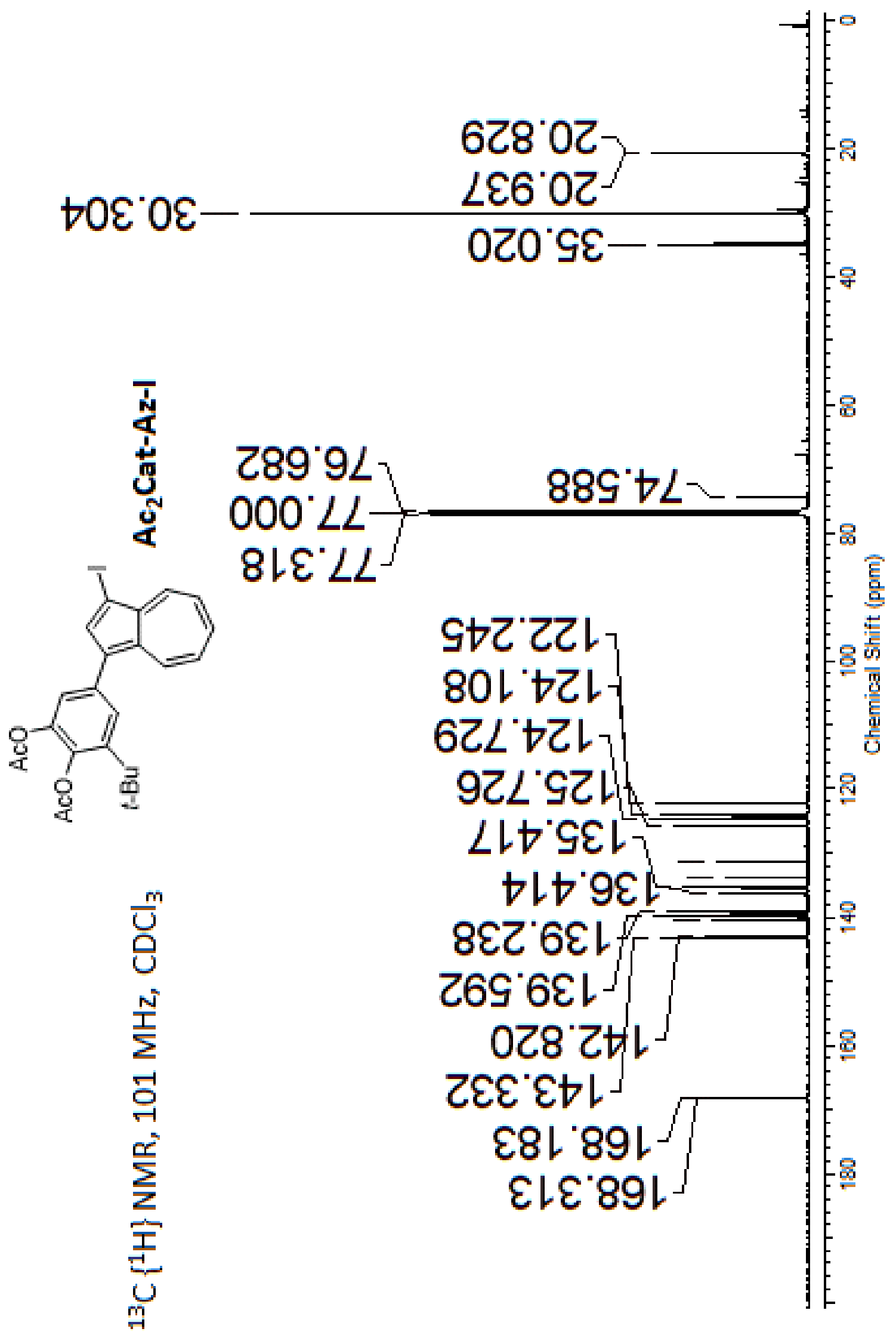




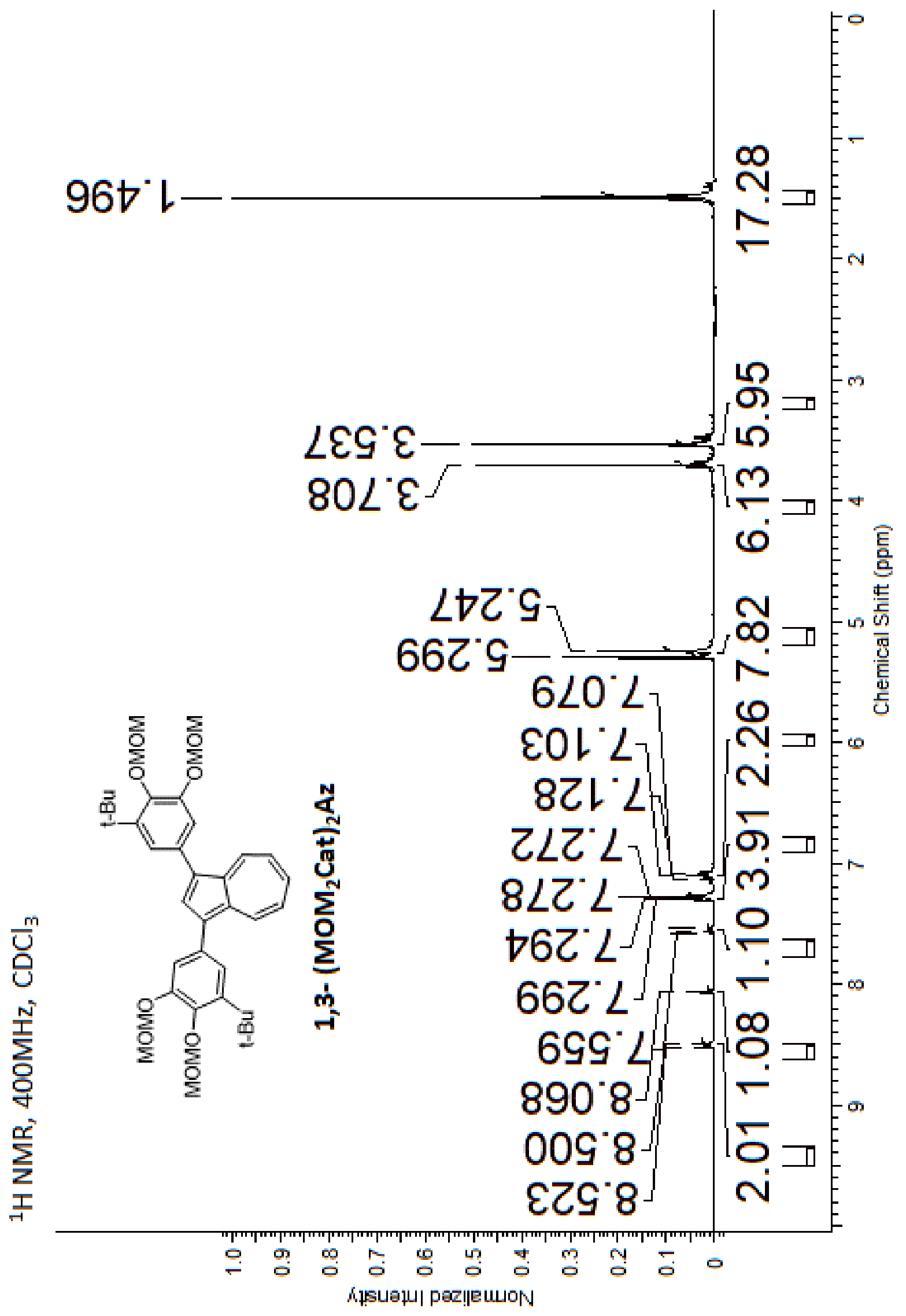




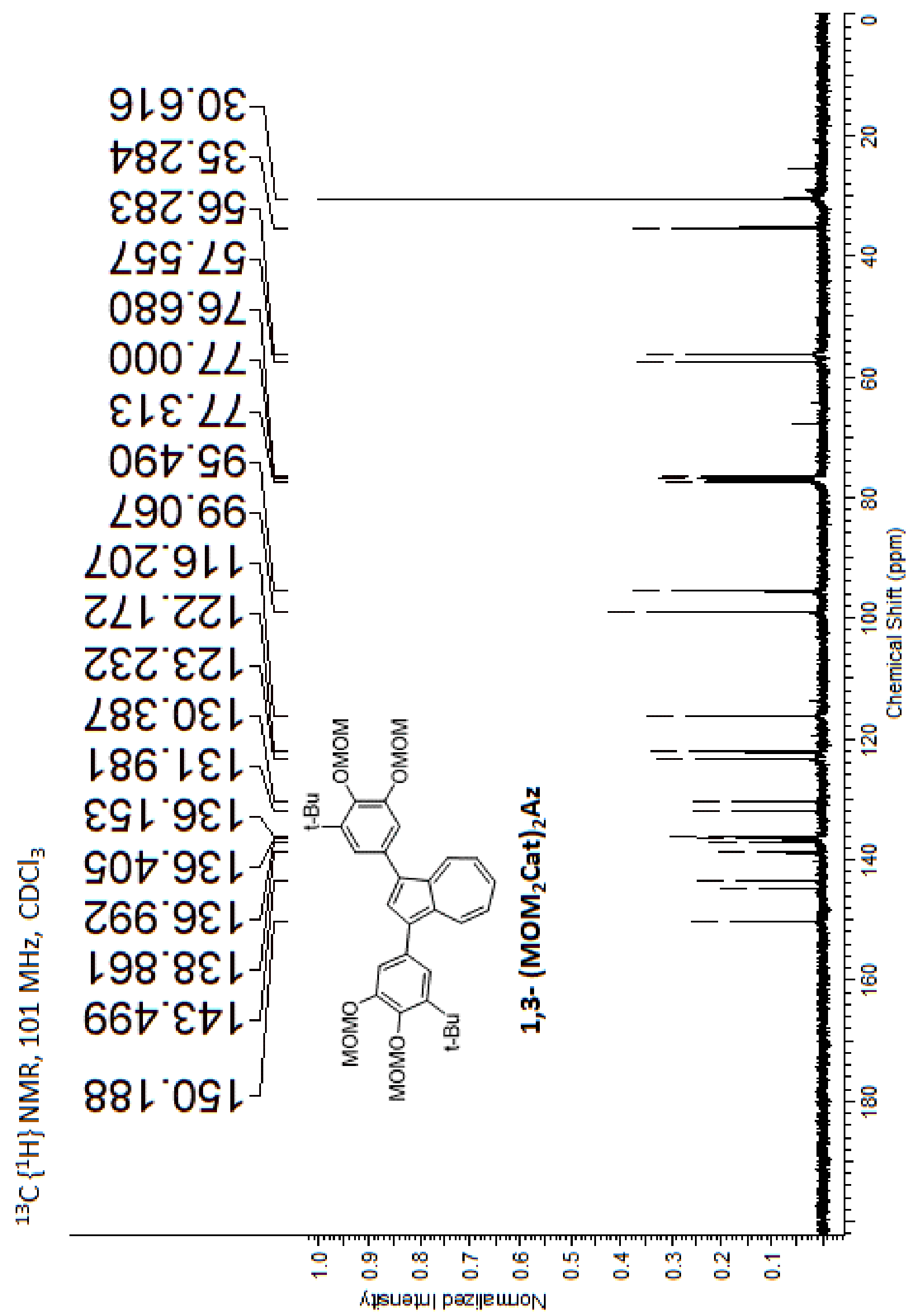




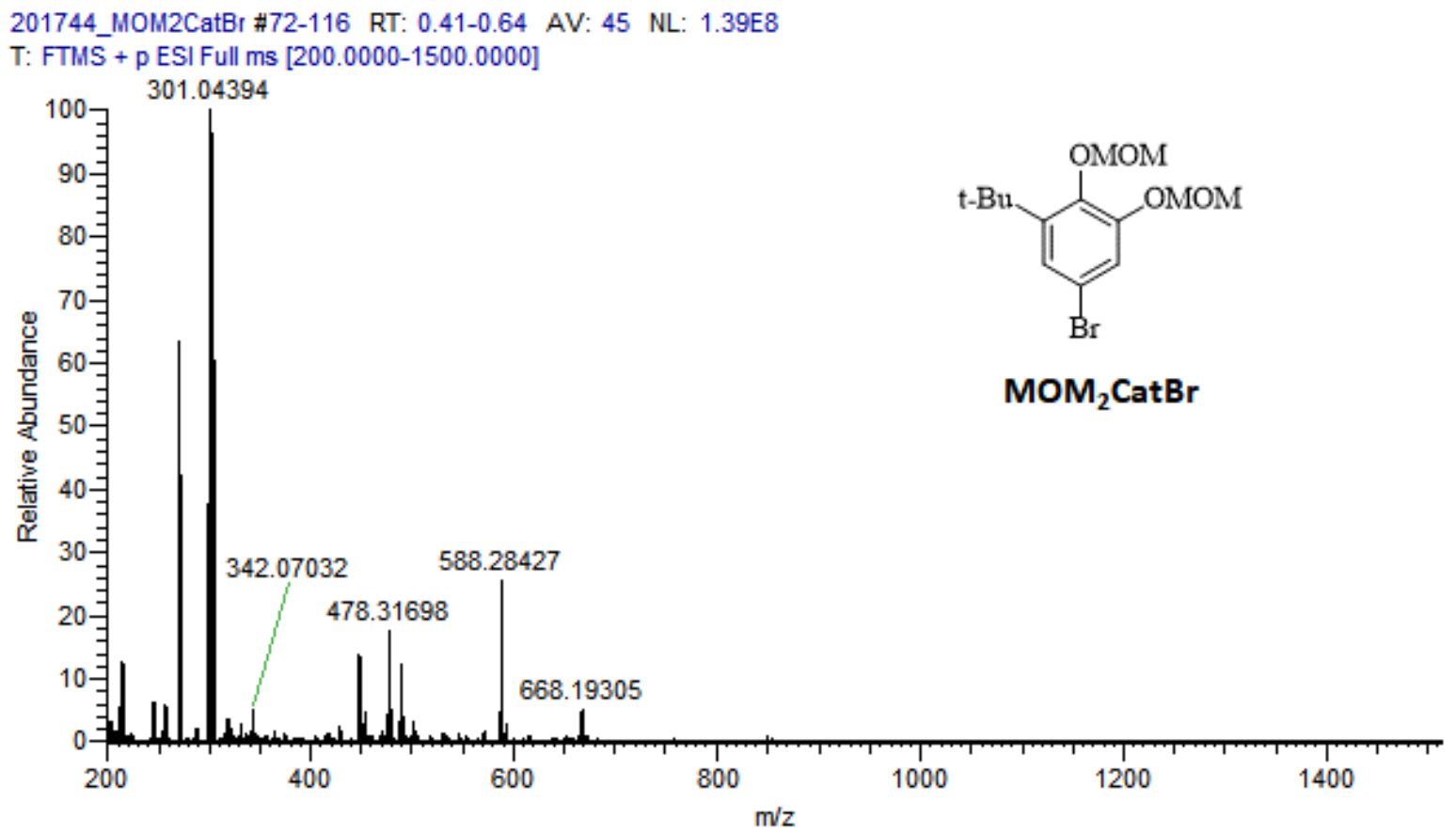

MOM2CatBr Experimental and Theoretical Isotopic Distribution

for $\mathrm{C}_{14} \mathrm{H}_{21} \mathrm{BrO}_{4}[\mathrm{M}+\mathrm{Nal}+$

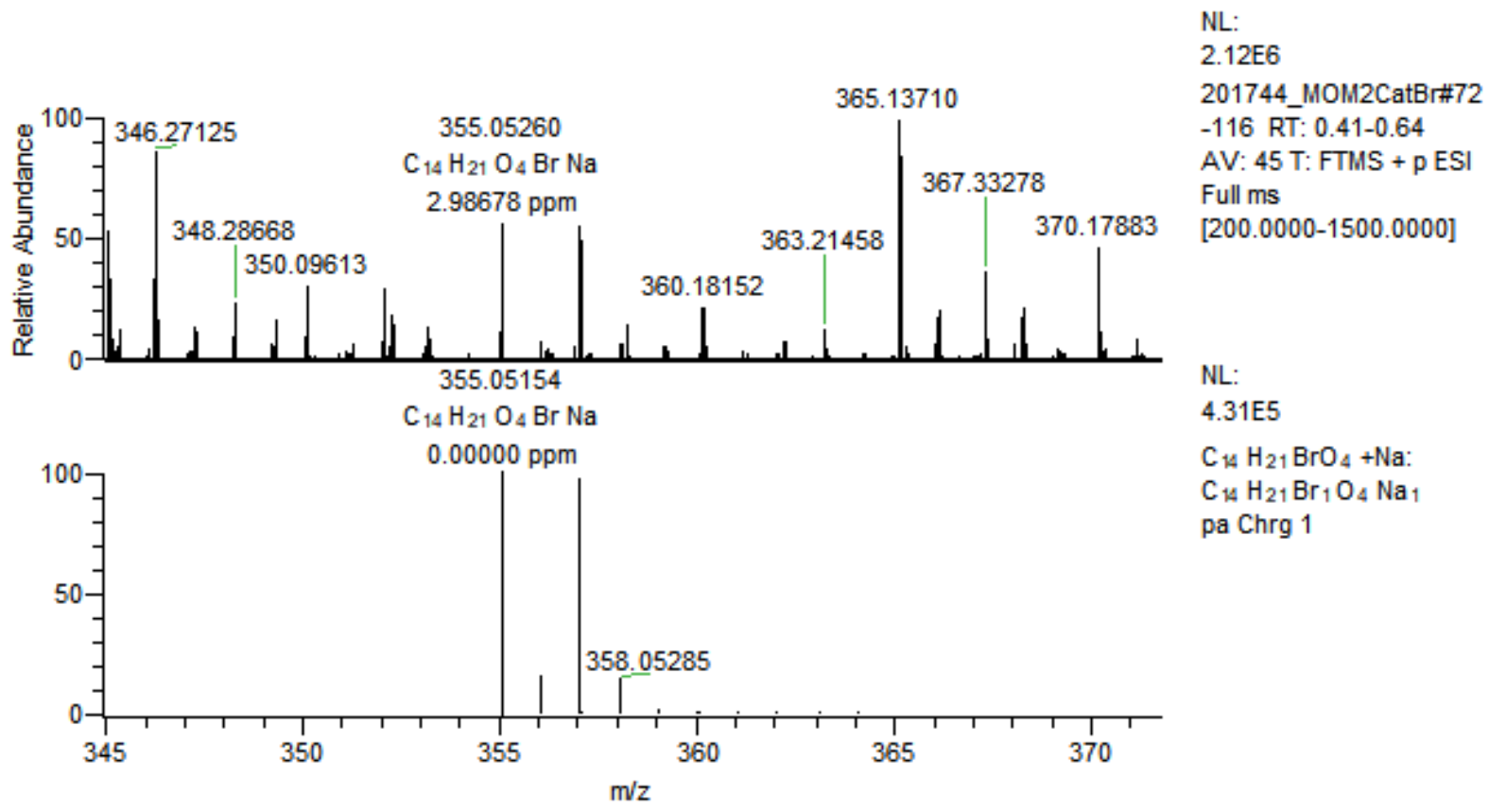


MOM2CatBpin Full Scan Positive Ion Mode

201840 MOM2CatBpin $\# 91-118$ RT: 0.52-0.68 AV: 28 NL: 7.61 B

T: FTMS + p ESI Full ms [200.0000-1000.0000]

100223.13235

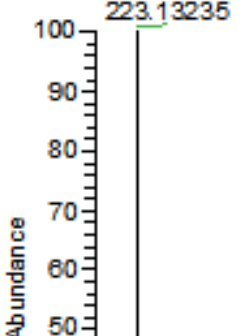<smiles>COc1cc(B2OC(C)(C)C(C)(C)O2)cc(C(C)(C)C)c1OC</smiles>

$\mathrm{MOM}_{2}$ CatBpin

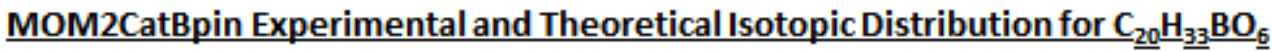

$\left[\mathrm{M}+\mathrm{Nal}^{+}\right.$

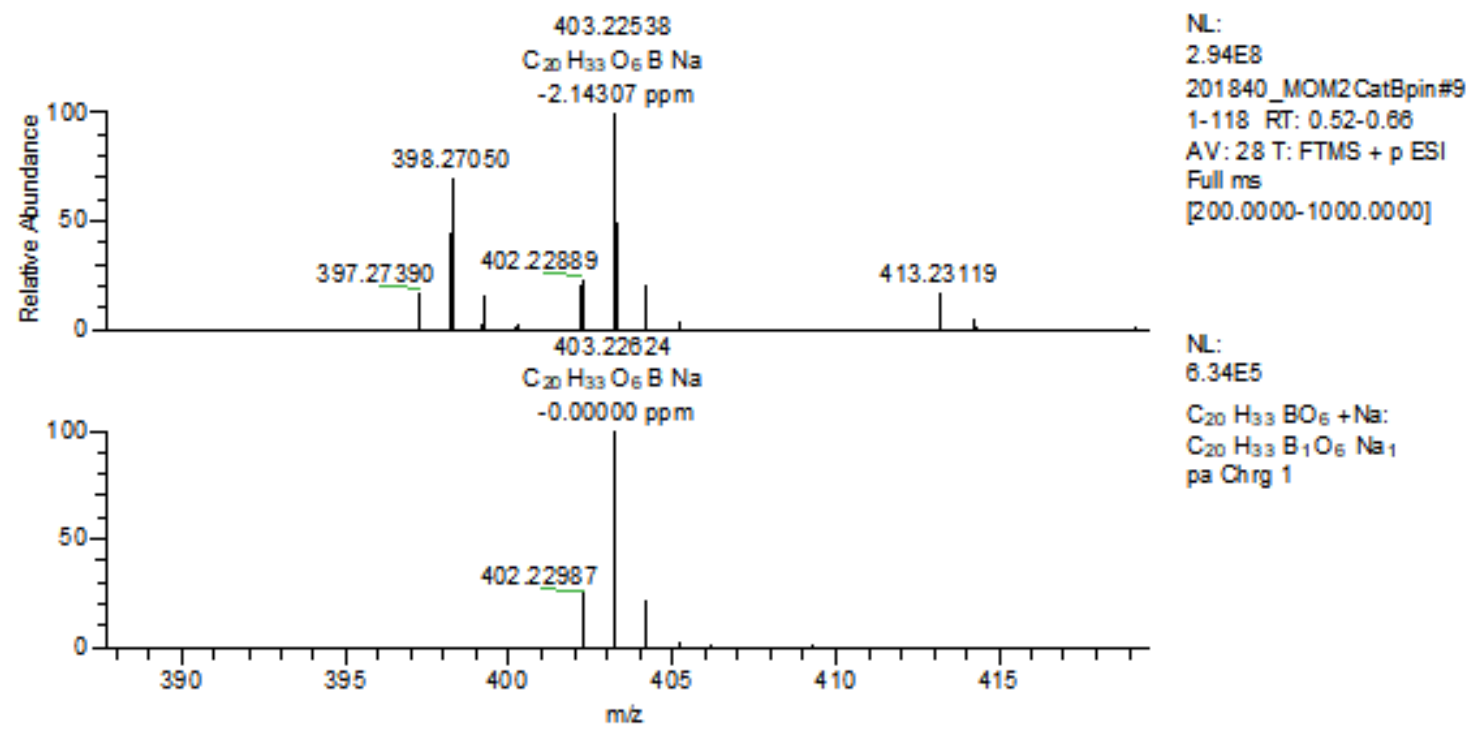




\section{Az-PhOH Total Ion Chromatogram Positive Ion Mode}

200216_1-4 \#70-87 RT: $0.41-0.50$ AV: 18 NL: $1.42 E 9$

T: FTMS + p ESIFull ms [200.0000-1500.0000]

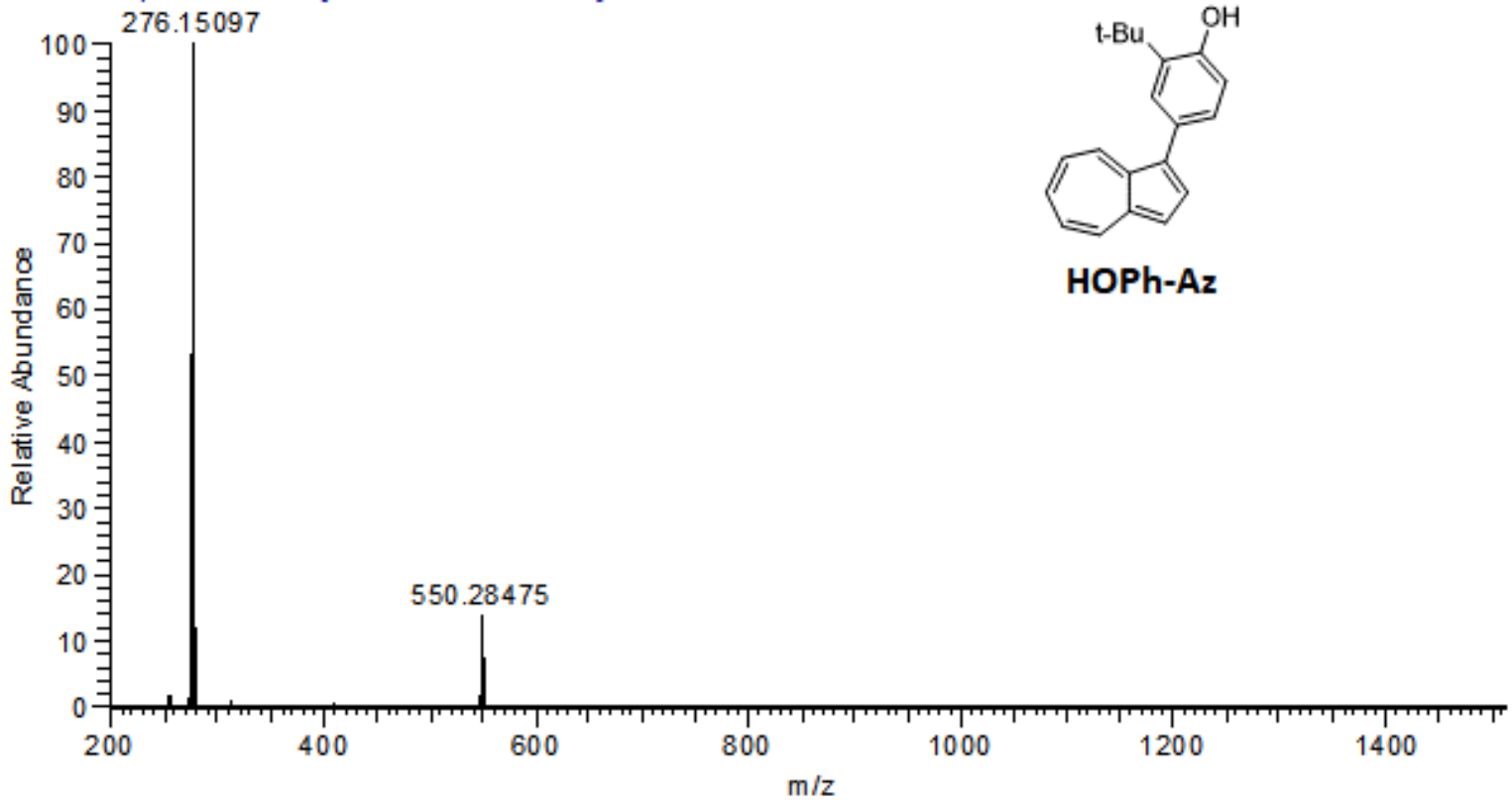

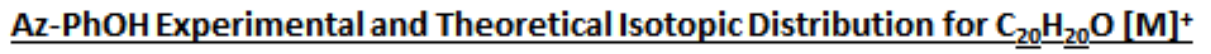

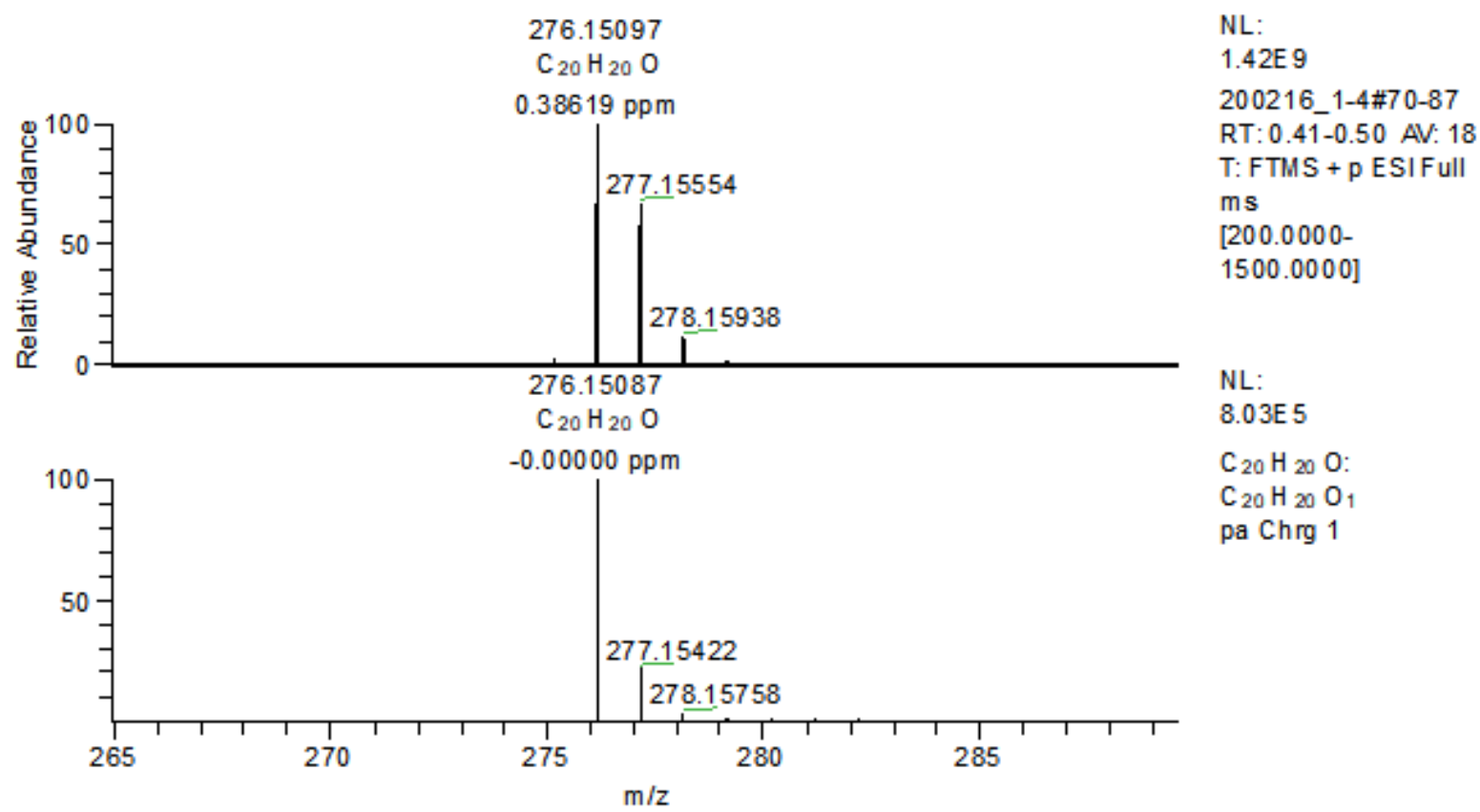




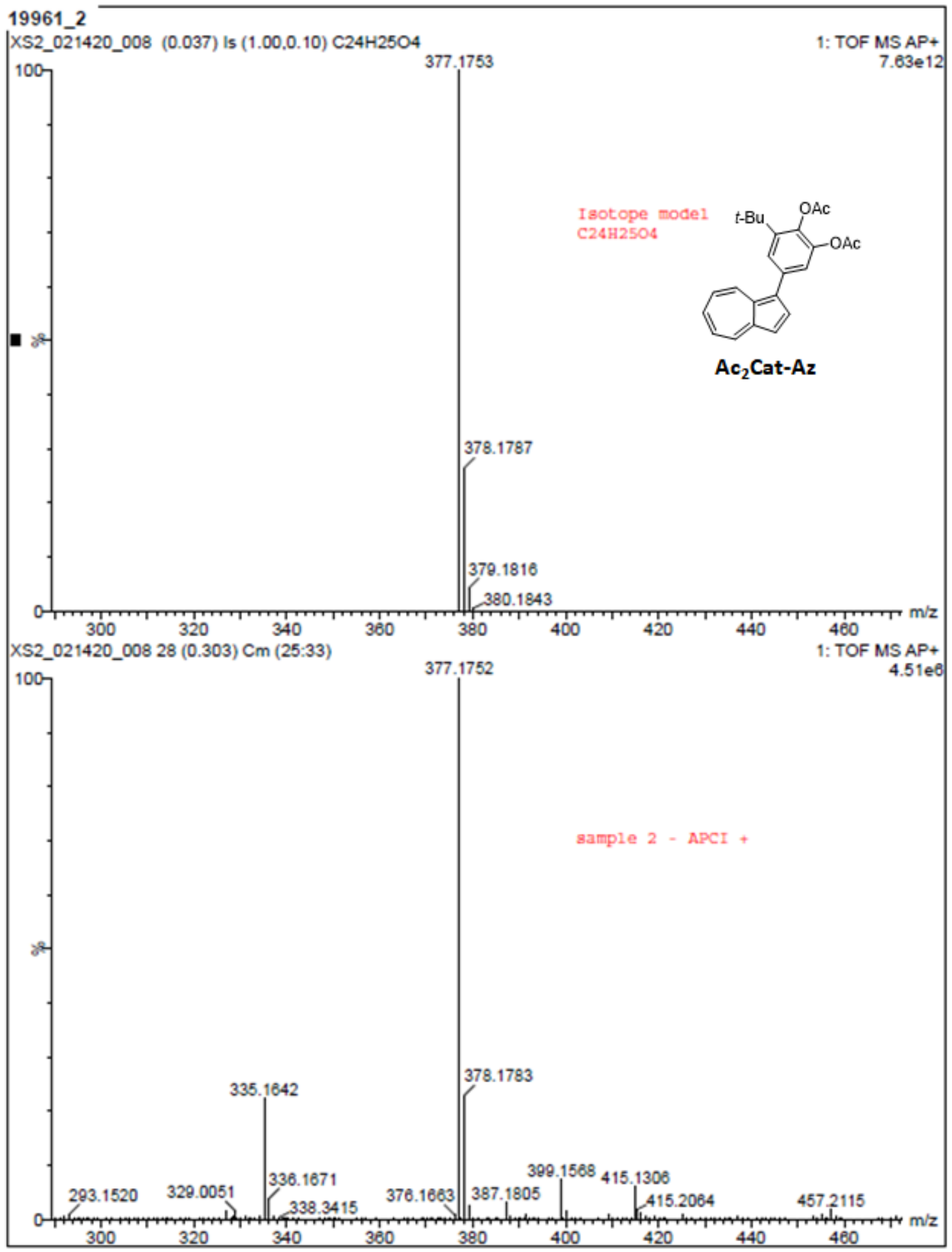




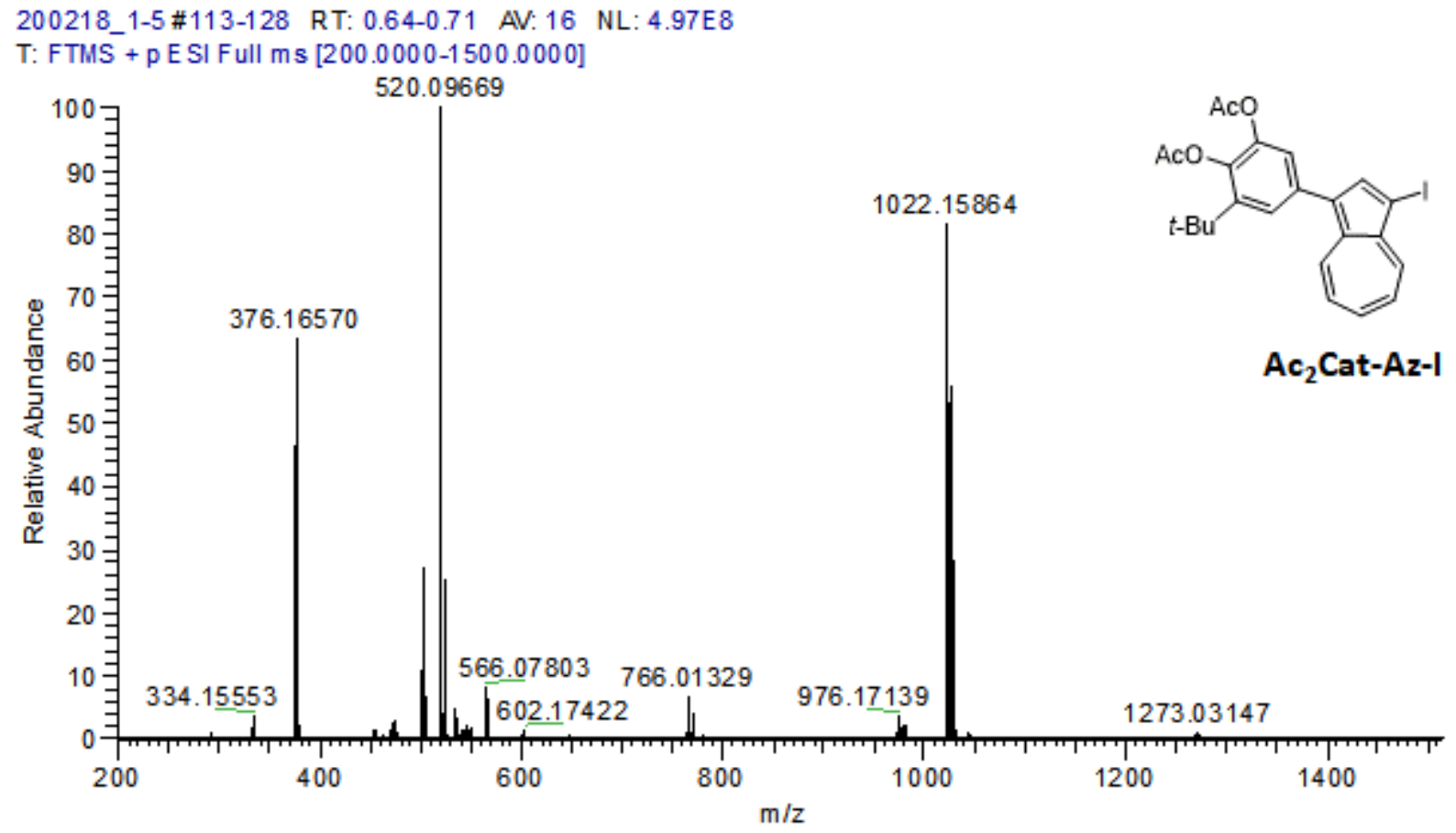

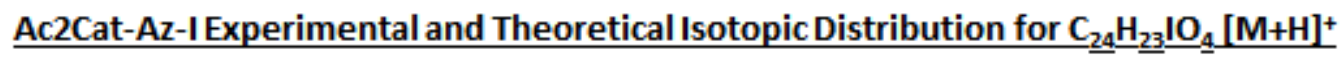

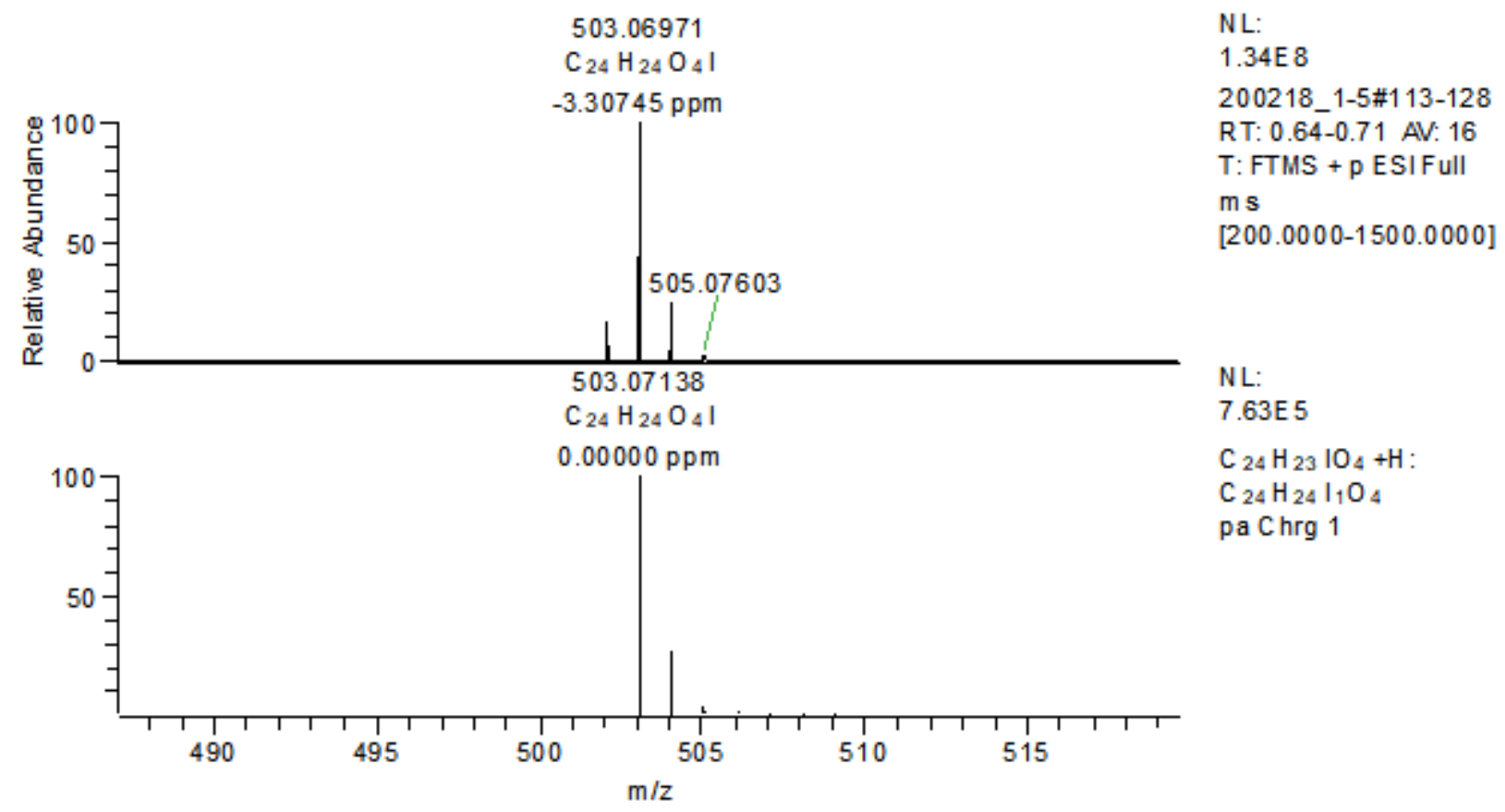



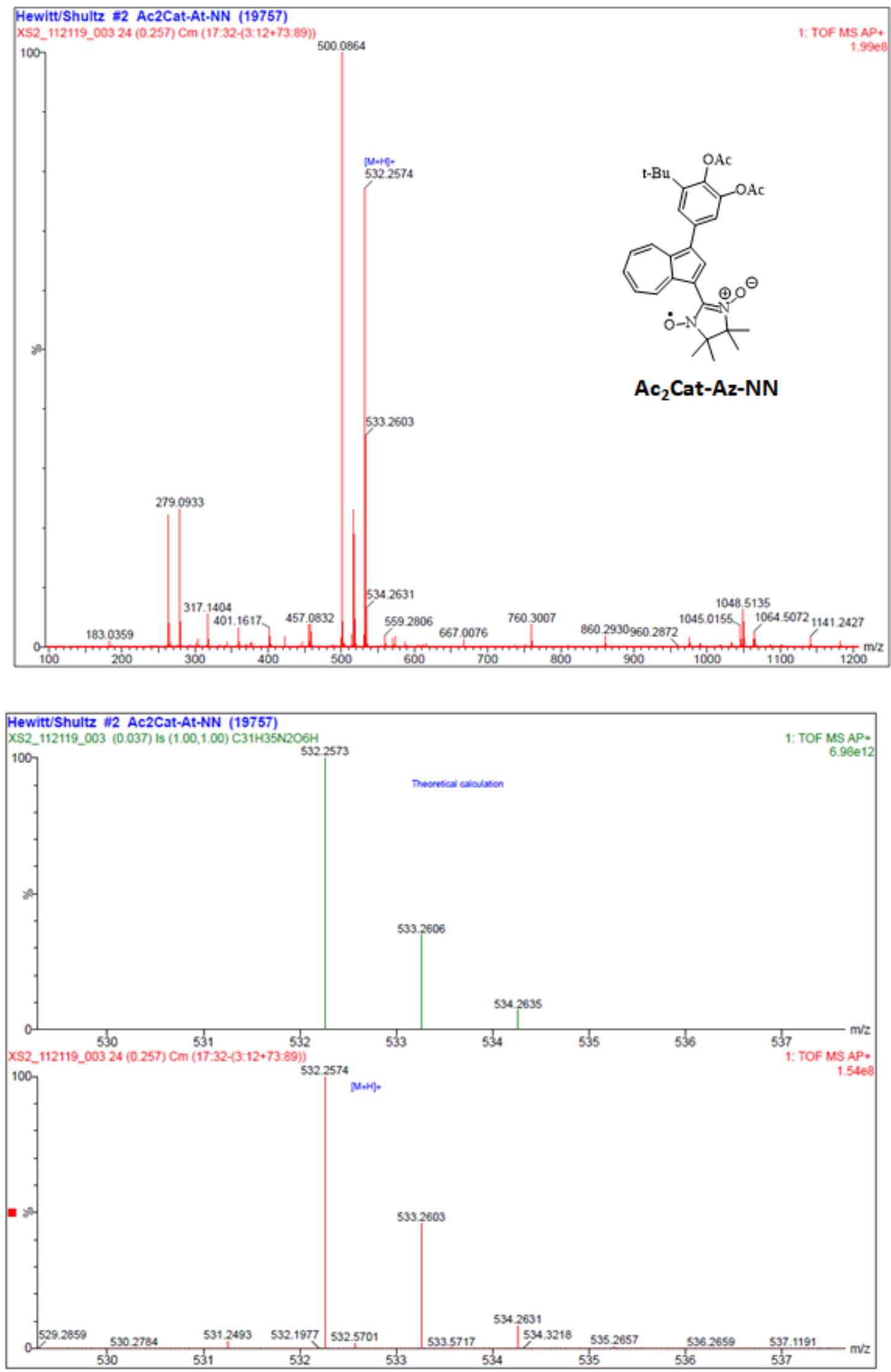

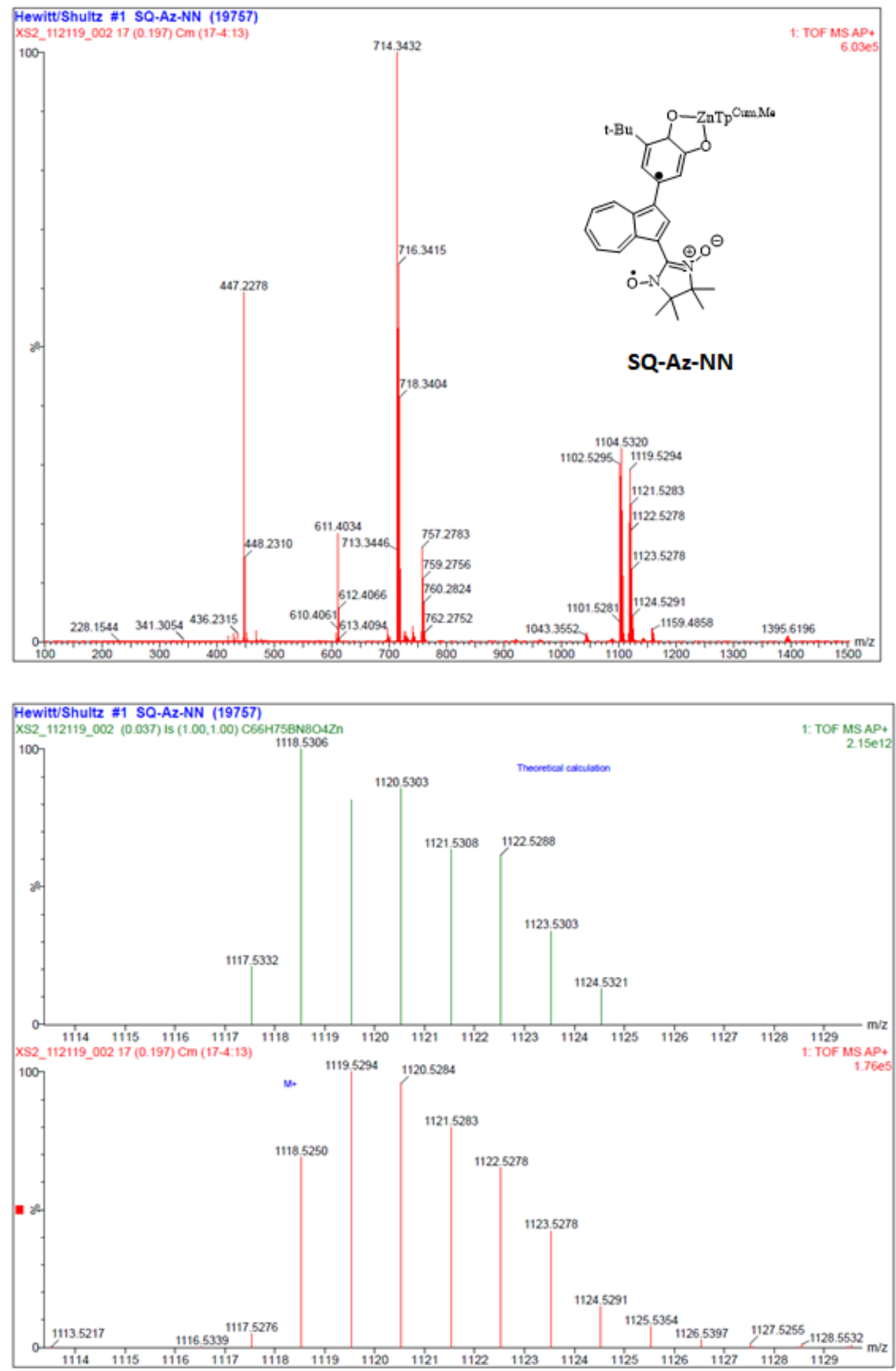

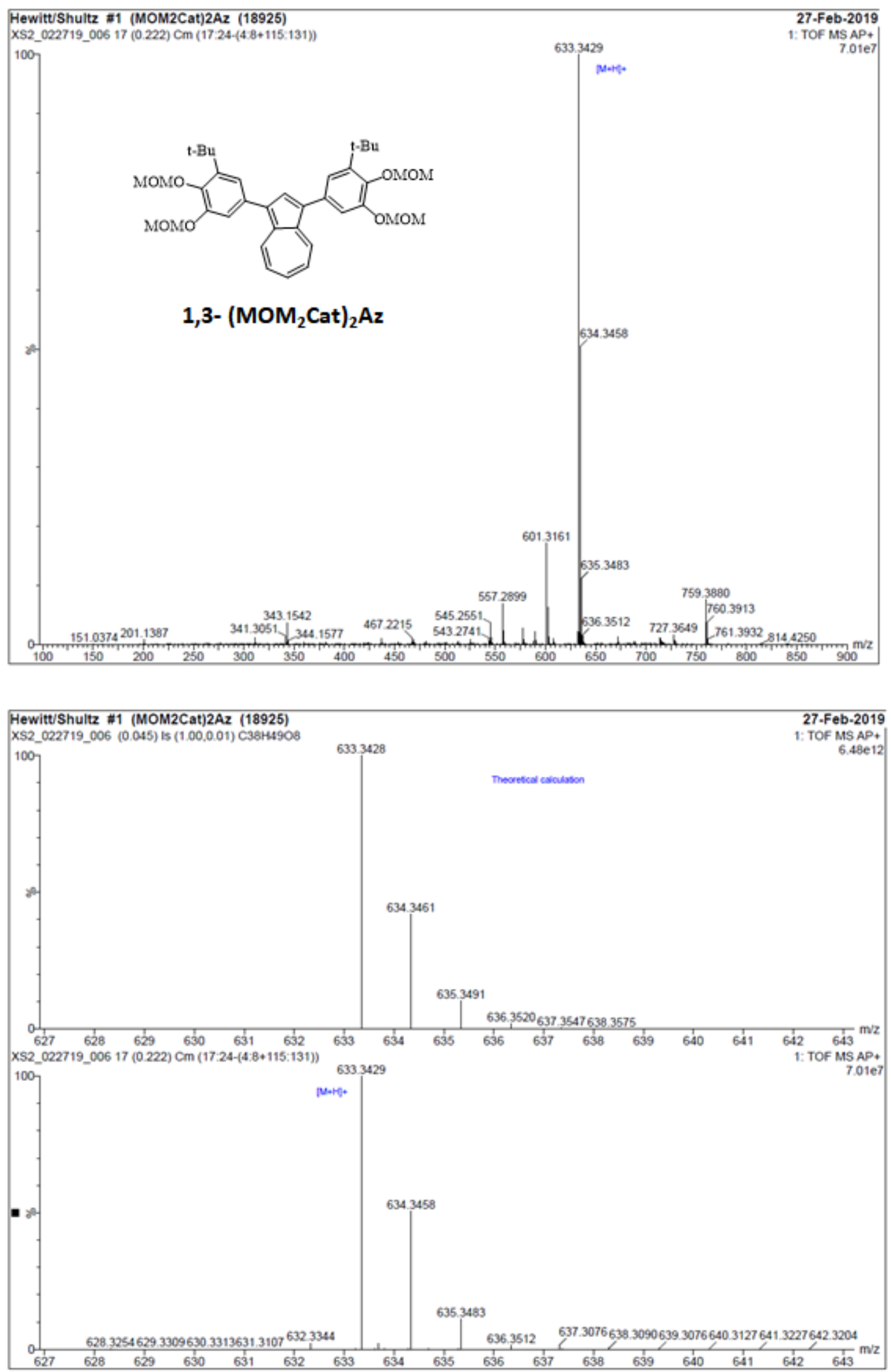

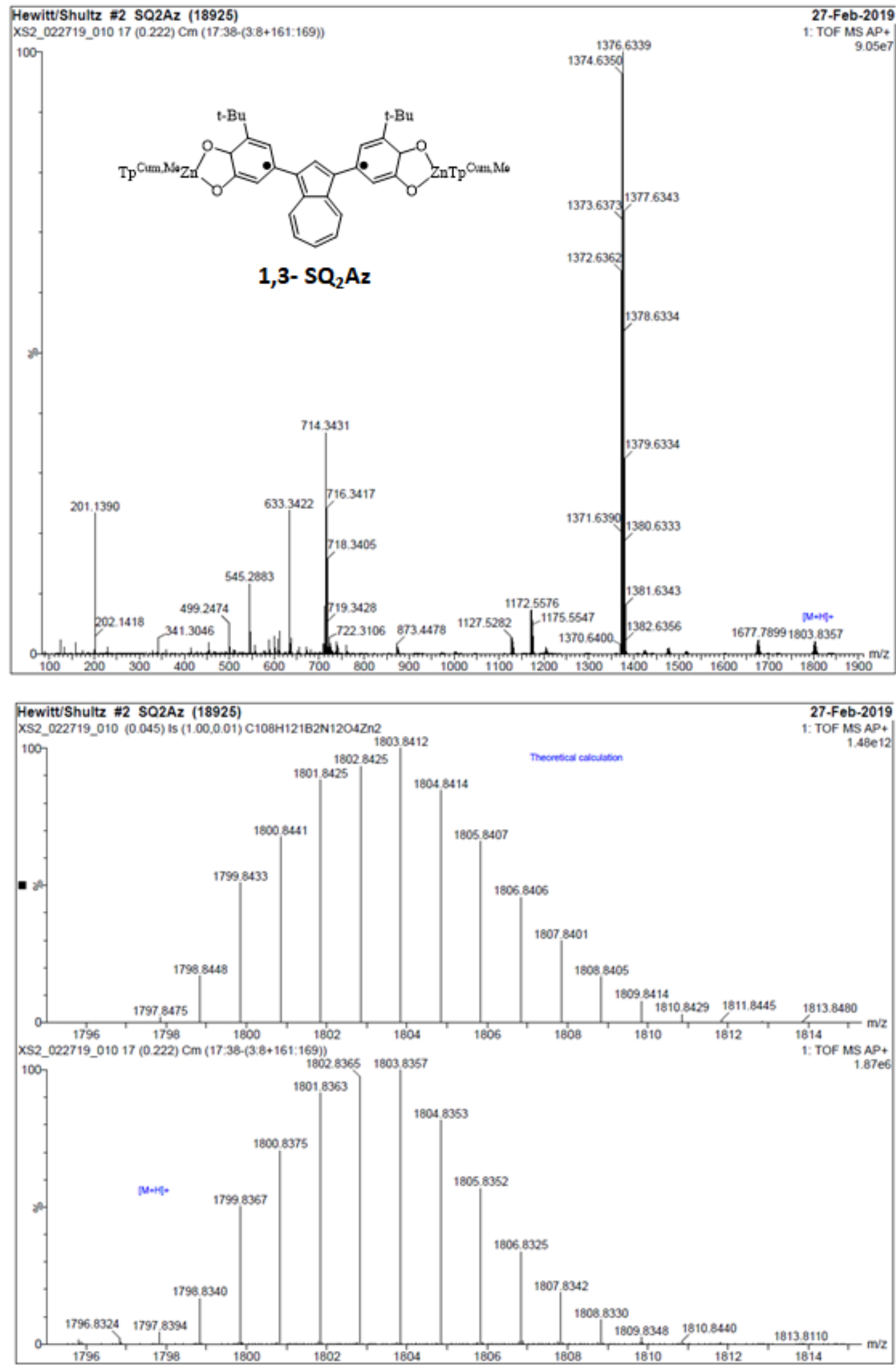


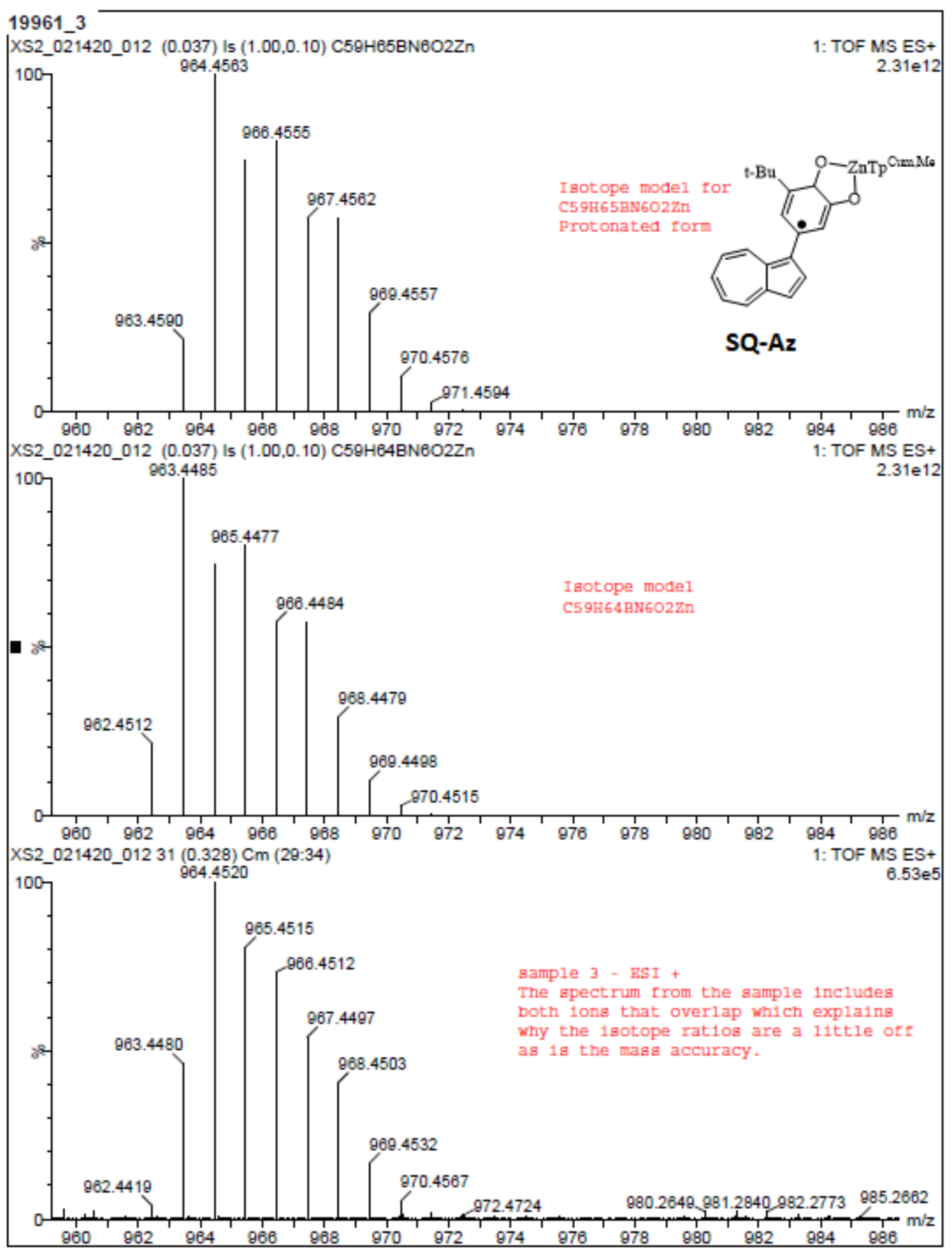




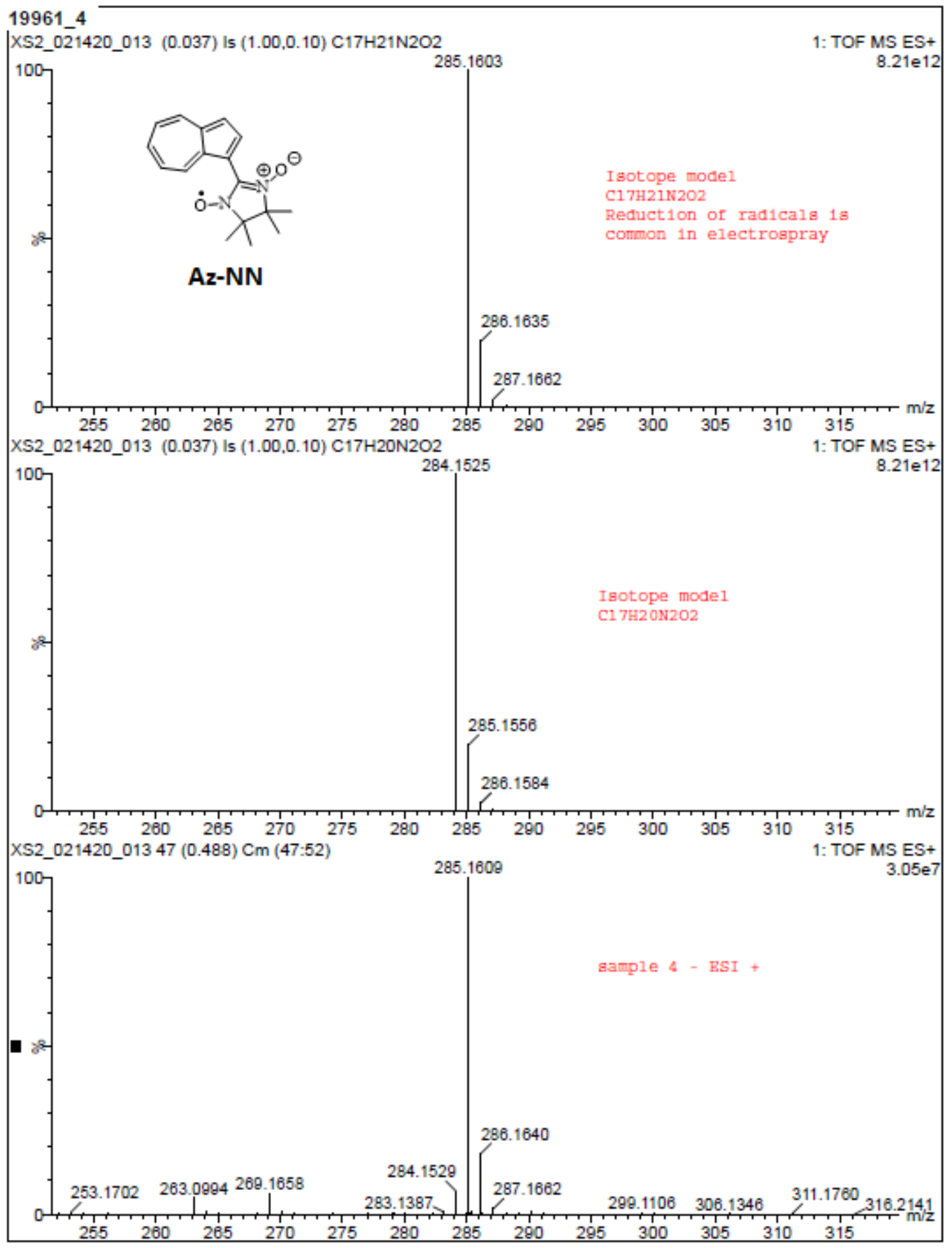

